\title{
Analysis of Vehicle Steering and Driving Bifurcation Characteristics
}

\author{
Xianbin Wang ${ }^{1,2}$ and Shuming Shi ${ }^{2}$ \\ ${ }^{1}$ Traffic College, Northeast Forestry University, Harbin, Heilongjiang 150040, China \\ ${ }^{2}$ Traffic College, Jilin University, Changchun, Jilin 130025, China \\ Correspondence should be addressed to Xianbin Wang; xbwang10@163.com
}

Received 25 April 2015; Revised 15 July 2015; Accepted 22 July 2015

Academic Editor: Giuseppe Rega

Copyright (c) $2015 \mathrm{X}$. Wang and S. Shi. This is an open access article distributed under the Creative Commons Attribution License, which permits unrestricted use, distribution, and reproduction in any medium, provided the original work is properly cited.

\begin{abstract}
The typical method of vehicle steering bifurcation analysis is based on the nonlinear autonomous vehicle model deriving from the classic two degrees of freedom (2DOF) linear vehicle model. This method usually neglects the driving effect on steering bifurcation characteristics. However, in the steering and driving combined conditions, the tyre under different driving conditions can provide different lateral force. The steering bifurcation mechanism without the driving effect is not able to fully reveal the vehicle steering and driving bifurcation characteristics. Aiming at the aforementioned problem, this paper analyzed the vehicle steering and driving bifurcation characteristics with the consideration of driving effect. Based on the 5DOF vehicle system dynamics model with the consideration of driving effect, the 7DOF autonomous system model was established. The vehicle steering and driving bifurcation dynamic characteristics were analyzed with different driving mode and driving torque. Taking the front-wheel-drive system as an example, the dynamic evolution process of steering and driving bifurcation was analyzed by phase space, system state variables, power spectral density, and Lyapunov index. The numerical recognition results of chaos were also provided. The research results show that the driving mode and driving torque have the obvious effect on steering and driving bifurcation characteristics.
\end{abstract}

\section{Introduction}

In recent years, with the development of tyre mechanics and nonlinear dynamics theory, the fact that the vehicle dynamics bifurcation mechanism due to nonlinear characteristics of the tyre lateral force has been basically confirmed [1-3]. The 2DOF vehicle model assumes that the longitudinal velocity is constant and does not consider the effect of tyre longitudinal force on the system stability [4]. But, under the steering and driving conditions, with the increase of the longitudinal velocity, the tyres have to provide more longitudinal driving force. From the essence of dynamic mechanics, this phenomenon is caused by the combined slip characteristics of tyre longitudinal and lateral forces and the coupling effect of multidegree of freedom.

Tyres under different driving conditions can provide various lateral forces. Therefore, the steering bifurcation mechanism without driving torque involved cannot fully reveal the vehicle steering and driving bifurcation characteristics and also cannot explain driving torque effects on vehicle handling stability. The bifurcation analysis is usually based on the nonlinear vehicle model deriving from the classic 2DOF linear vehicle model. In the steering bifurcation analysis, the most representative research result is the phase plane of vehicle body sideslip angle and body sideslip angle rate proposed by Inagaki [5] in 1994. Using the method of Inagaki, Ono $[6,7]$ also got the same conclusion that vehicle system had three equilibrium points. One was the stable focus; the other two were unstable saddle points. Ono also found that when the body sideslip angle increased to a certain extent, vehicle instability was mainly caused by the saddle node bifurcation. Shen et al. [8] used the geometry trajectory intersection method to study the stability of vehicle steering dynamics. Their results also were close to Inagaki's conclusion; namely, the vehicle steering dynamics system had three equilibrium points. One was a stable focus and 
the other two were instable saddle points. On the basis of 2 DOF vehicle model, longitudinal velocity was added into the vehicle body model by Liu et al. [9]. As a result, the constant longitudinal velocity assumption was removed, and the stability criterion based on the 2DOF model was revised. Furthermore, the chaos phenomenon of the vehicle steering movement was found. And it reflected that the dynamics essential of vehicle steering instability was the chaotic motion [10]. Horiuchi et al. [11] proposed a method of analyzing the vehicle stability during acceleration and braking adopting constrained bifurcation and continuation methods. Based on the vehicle model including the longitudinal velocity, lateral velocity, yaw rate, and roll velocity, the bifurcation caused by the braking deceleration was analyzed. According to the wheel rotation dynamics analysis, the classical tire longitudinal slip rate equation was verified under instable driving situation by Wang et al. [12]. And on the basis of 5DOF nonlinear vehicle model including the driving effect the driving mode effects on vehicle stability with different steering angle input were analyzed.

Above all, by employing the $2 \mathrm{DOF}$ vehicle model, the vehicle steering stability study has achieved fruitful research results. The 3DOF vehicle model including the longitudinal velocity reveals the chaos motion nature of the vehicle instability. The 5DOF vehicle model containing the driving force indicates that different driving modes affect vehicle steering stability. However, the dynamic evolution process of vehicle steering and driving bifurcation still lacks the comprehensive research, especially the fully accurate numerical recognition results of chaos.

\section{Vehicle System Model}

2.1. 5DOF Vehicle System Model. Based on the $3 \mathrm{DOF}$ vehicle steering model [13], the 5DOF [12] planar motion nonlinear dynamics vehicle system model with driving torque involved is established. The equations of 5DOF vehicle model are shown in (1). Figure 1 is the sketch of the bicycle vehicle model:

$$
\begin{aligned}
\dot{v}_{x}= & v_{y} \omega \\
& +\frac{\left(F_{l f} \cos \delta_{f}-F_{s f} \sin \delta_{f}+F_{l r}-\operatorname{sgn}\left(v_{x}\right) \cdot C_{\text {air } \_x} A_{L_{-} x}(\rho / 2) v_{x}^{2}\right)}{m}, \\
\dot{v}_{y}= & -v_{x} \omega \\
& +\frac{\left(F_{l f} \sin \delta_{f}+F_{s f} \cos \delta_{f}+F_{s r}-\operatorname{sgn}\left(v_{y}\right) \cdot C_{\text {air }-y} A_{L_{-} y}(\rho / 2) v_{y}^{2}\right)}{m}, \\
\dot{\omega}= & \frac{\left(F_{l f} \sin \delta_{f}+F_{s f} \cos \delta_{f}\right) l_{f}-F_{s r} l_{r}}{I_{z}}, \\
\dot{\omega}_{f}= & \frac{T_{d}-\operatorname{sgn}\left(\omega_{f}\right) \cdot T_{b f}-R_{e} \cdot F_{l f}}{J}, \\
\dot{\omega}_{r}= & \frac{T_{d}-\operatorname{sgn}\left(\omega_{r}\right) \cdot T_{b r}-R_{e} \cdot F_{l r}}{J},
\end{aligned}
$$

where $m$ is vehicle mass; $I_{z}$ is vehicle yaw moment of inertia; $v_{x}$ is longitudinal velocity; $v_{y}$ is lateral velocity; $\omega$ is yaw rate;

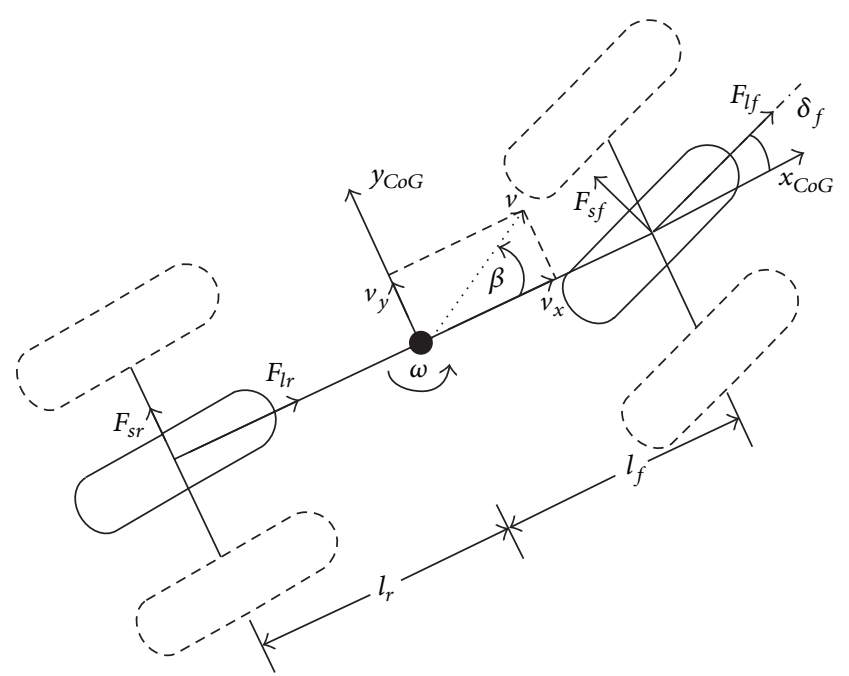

Figure 1: Vehicle bicycle model.

TABLE 1: Vehicle parameters.

\begin{tabular}{lc}
\hline Parameters & Values \\
\hline$m / \mathrm{kg}$ & 1500 \\
$I_{z} / \mathrm{kg} \cdot \mathrm{m}^{2}$ & 3000 \\
$l_{f} / \mathrm{m}$ & 1.2 \\
$l_{r} / \mathrm{m}$ & 1.3 \\
$J / \mathrm{kg} \cdot \mathrm{m}^{2}$ & 1 \\
$C_{\text {air }-x} /$ & 0.3 \\
$C_{\text {air-y }} /$ & 0.4 \\
$A_{L-x} / \mathrm{m}^{2}$ & 1.7 \\
$A_{L-y} / \mathrm{m}^{2}$ & 3.5 \\
$\rho / \mathrm{kg} / \mathrm{m}^{3}$ & 1.29 \\
$R_{e} / \mathrm{m}$ & 0.224 \\
\hline
\end{tabular}

$\omega_{f}$ is angular velocity of front wheel; $\omega_{r}$ is angular velocity of rear wheel; $l_{f}$ is distance from front axle to the mass center; $l_{r}$ is distance from rear axle to the mass center; $J$ is wheel moment of inertia; $\delta_{f}$ is front wheel steering angle; $C_{\text {air }-x}$, $C_{\text {air }-y}$ are longitudinal and lateral air resistance coefficient; $A_{L_{-}-x}, A_{L_{-} y}$ are vehicle longitudinal and lateral area; $\rho$ is air density; $T_{d}$ is driving torque; $T_{b}$ is braking torque; $R_{e}$ is wheel rolling radius; $F_{l f}, F_{l r}, F_{s f}$, and $F_{s r}$ are longitudinal and lateral tyre force of front and rear wheel.

The vehicle parameters are listed in Table 1.

The tyre force is modeled by the Magic Formula [14]:

$$
F=D \sin (C \arctan (B x-E(B x-\arctan B x))),
$$

where $B, C, D$, and $E$ are coefficients. $F$ is the longitudinal or lateral tyre force, and $x$ is the longitudinal slip or sideslip angle.

The typical longitudinal slip [14] is defined as follows:

$$
k=\frac{\omega_{w} \cdot R_{e}-v_{w x}}{v_{w x}},
$$

where $\omega_{w}$ is angular velocity of wheel; $v_{w x}$ is linear velocity at the wheel center in the longitudinal direction. 
TABLE 2: Longitudinal tyre parameters.

\begin{tabular}{lcccc}
\hline \multirow{2}{*}{ Tyre } & \multicolumn{4}{c}{ Coefficient } \\
& $B$ & $C$ & $D$ & $E$ \\
\hline Front tyre & 11.275 & 1.56 & 2574.8 & 0.4109 \\
Rear tyre & 18.631 & 1.56 & 1749.6 & 0.4108 \\
\hline
\end{tabular}

TABLE 3: Lateral tyre parameters.

\begin{tabular}{lcccc}
\hline \multirow{2}{*}{ Tyre } & \multicolumn{4}{c}{ Coefficient } \\
& $B$ & $C$ & $D$ & $E$ \\
\hline Front tyre & 11.275 & 1.56 & 2574.7 & -1.999 \\
Rear tyre & 18.631 & 1.56 & 1749.7 & -1.7908 \\
\hline
\end{tabular}

TABle 4: Combined slip coefficient.

\begin{tabular}{lccc}
\hline \multicolumn{2}{c}{ Longitudinal slip coefficient } & \multicolumn{2}{c}{ Lateral slip coefficient } \\
$r_{x, 1}$ & $r_{x, 2}$ & $r_{y, 1}$ & $r_{y, 2}$ \\
\hline 35 & 40 & 40 & 35 \\
\hline
\end{tabular}

The longitudinal tyre parameters are listed in Table 2.

The sideslip angles of front and rear tyre are given in the following:

$$
\begin{aligned}
& \alpha_{f}=\delta_{f}-a \tan \left(\frac{v_{y}+\omega \cdot l_{f}}{v_{x}}\right), \\
& \alpha_{r}=\delta_{r}-a \tan \left(\frac{v_{y}-\omega \cdot l_{r}}{v_{x}}\right),
\end{aligned}
$$

where $\delta_{r}=0$.

Table 3 shows the lateral tyre parameters [15].

Figures 2 and 3 show the steady state tyre characteristics of the longitudinal force and lateral tire force.

By using models proposed by Pacejka [14], the combined slip characteristics, the tyre forces can be calculated as follows:

$$
\begin{aligned}
F_{l f} & =F_{l f 0} \cdot G_{x}, \\
F_{l r} & =F_{l r 0} \cdot G_{x}, \\
G_{x} & =\cos \left[\arctan \left\{B_{g, x}(\alpha) \cdot \alpha\right\}\right], \\
B_{g, x}(\alpha) & =r_{x, 1} \cos \left[\arctan \left(r_{x, 2} \cdot k\right)\right], \\
F_{s f} & =G_{y} \cdot F_{s f 0}, \\
F_{s r} & =G_{y} \cdot F_{s r 0}, \\
G_{y} & =\cos \left[\arctan \left\{B_{g, y}(k) \cdot k\right\}\right], \\
B_{g, y}(k) & =r_{y, 1} \cos \left[\arctan \left(r_{y, 2} \cdot \alpha\right)\right],
\end{aligned}
$$

where $F_{l f 0}, F_{l r 0}, F_{s f 0}$, and $F_{s r 0}$ are steady state tyre force, calculated by Magic Formula, (2); $G_{x}, G_{y}$ are tyre force weighting function; $r_{x, 1}, r_{x, 2}, r_{y, 1}$, and $r_{y, 2}$ are combined slip coefficient.

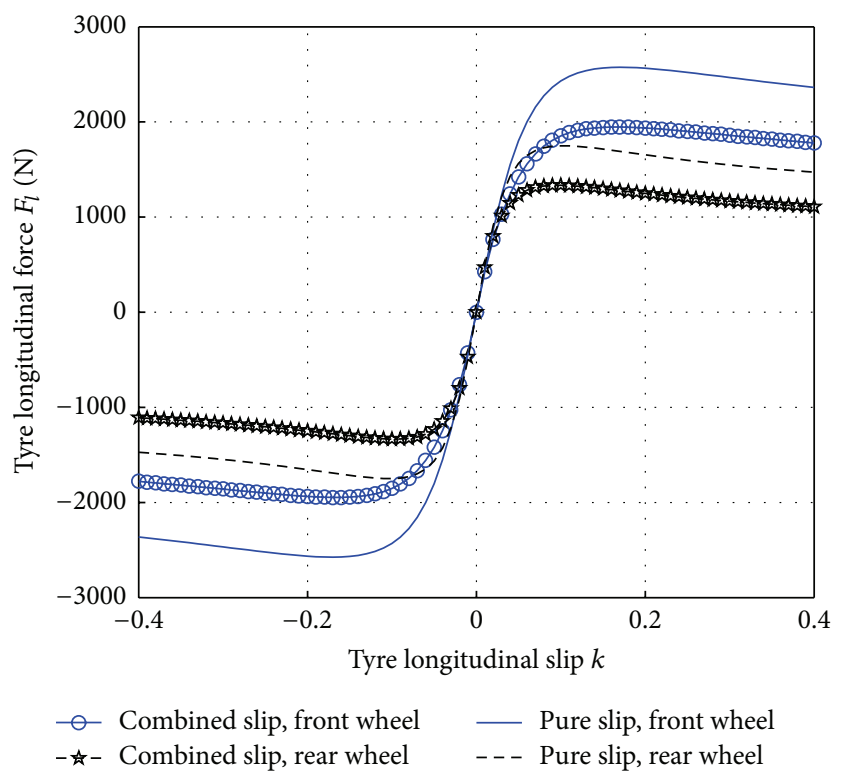

FIGURE 2: Steady state tyre characteristics.

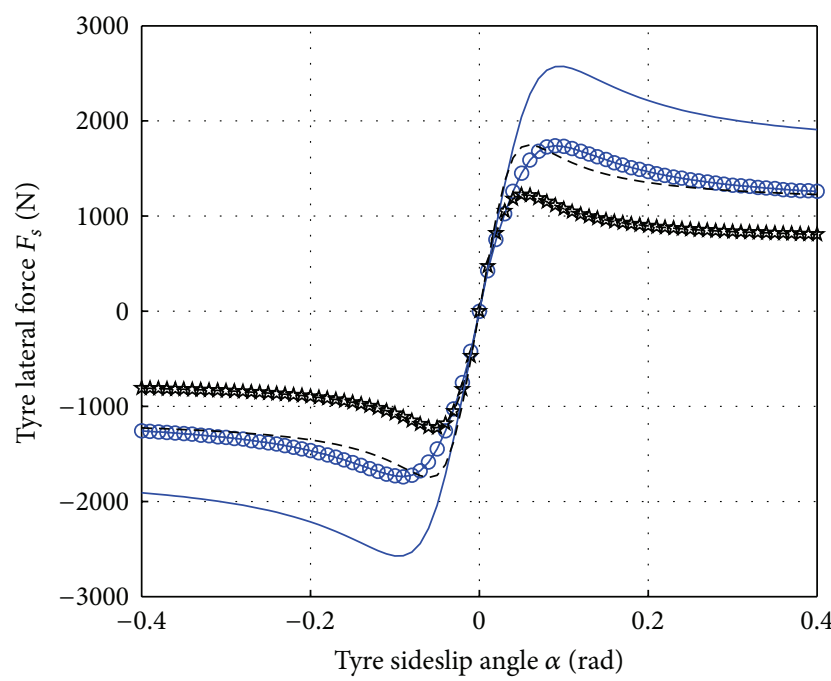

$\begin{array}{lll}- & \text { Combined slip, front wheel } \quad \text { Pure slip, front wheel } \\ -\downarrow-\text { Combined slip, rear wheel } & --- \text { Pure slip, rear wheel }\end{array}$

FIGURE 3: Steady state tyre characteristics.

The best interactive curves are produced with parameters mentioned in Table 4.

2.2. 7DOF Autonomous System Model. In order to focus attention on the dynamics characteristics of the vehicle itself, an effective way of introducing periodic front wheel steering angle input into the model without the driver model is establishing the autonomous model.

The typical vehicle handling stability test condition is selected. The front wheel steering angle input is the sinusoidal form as follows:

$$
\delta_{f}=A \sin \omega_{s f} t
$$


where $A$ is amplitude of front wheel angle input; $\omega_{s f}$ is frequency of front wheel angle input.

The 5DOF vehicle system model is transformed into 7DOF autonomous system model with the front wheel steering angle as an intermediate variable:

$$
\dot{X}=f(X),
$$

where $X=\left(v_{y}, \omega, v_{x}, \omega_{f}, \omega_{r}, \delta_{f}, z\right)$ and $z$ is intermediate variable:

$$
\begin{aligned}
z & =\omega_{s f} \cos \omega_{s f} t \\
\dot{v}_{x} & =v_{y} \omega \\
& +\frac{\left(F_{l f} \cos \delta_{f}-F_{s f} \sin \delta_{f}+F_{l r}-\operatorname{sgn}\left(v_{x}\right) \cdot C_{\text {air }-x} A_{L-x}(\rho / 2) v_{x}^{2}\right)}{m}, \\
\dot{v}_{y}= & -v_{x} \omega \\
& +\frac{\left(F_{l f} \sin \delta_{f}+F_{s f} \cos \delta_{f}+F_{s r}-\operatorname{sgn}\left(v_{y}\right) \cdot C_{\text {air }-y} A_{L_{-} y}(\rho / 2) v_{y}^{2}\right)}{m}, \\
\dot{\omega}^{2} & \frac{\left(F_{l f} \sin \delta_{f}+F_{s f} \cos \delta_{f}\right) l_{f}-F_{s r} l_{r}}{I_{z}} \\
\dot{\omega}_{f} & =\frac{T_{d}-\operatorname{sgn}\left(\omega_{f}\right) \cdot T_{b f}-R_{e} \cdot F_{l f}}{J}, \\
\dot{\omega}_{r} & =\frac{T_{d}-\operatorname{sgn}\left(\omega_{r}\right) \cdot T_{b r}-R_{e} \cdot F_{l r}}{J}, \\
\dot{\delta}_{f} & =A z \\
\dot{z}= & -\frac{\omega_{s f}^{2}}{A} \delta_{f} .
\end{aligned}
$$

\section{Amplitude of Front Wheel Angle Effect on Bifurcation Characteristics}

In order to be close to the practice vehicle operation condition, the steering and driving simulations under constant driving torque are carried out based on 7DOF autonomous system model.

The selection of driving torque is based on the related technical parameters of passenger car equipped with $1.6 \mathrm{~L}$ engine. In general, the maximum power of naturally aspirated engine is about $77 / 5600$ of $\mathrm{kw} / \mathrm{rmp}$ and the maximum engine torque is about $155 / 3500 \mathrm{Nm} / \mathrm{rpm}$. Therefore, the driving torque $T_{d}=140 \mathrm{Nm}$ is selected as the upper limit of the simulation. ing.

For the specific simulation parameters, we get the follow-

Initial longitudinal velocity $v_{x}=20 \mathrm{~m} / \mathrm{s}$. The constant driving torque on driving wheel $T_{d}=140 \mathrm{Nm}$. Note that, for all-wheel-drive mode, driving torque applying on the front and rear wheels is half of the total driving torque, respectively; namely, $T_{d}=70 \mathrm{Nm}$. The varying range of amplitude value of front wheel steering angle $A$ is $(0.0005,0.1) \mathrm{rad}$, with the interval value being $0.0005 \mathrm{rad}$. The frequency of front wheel

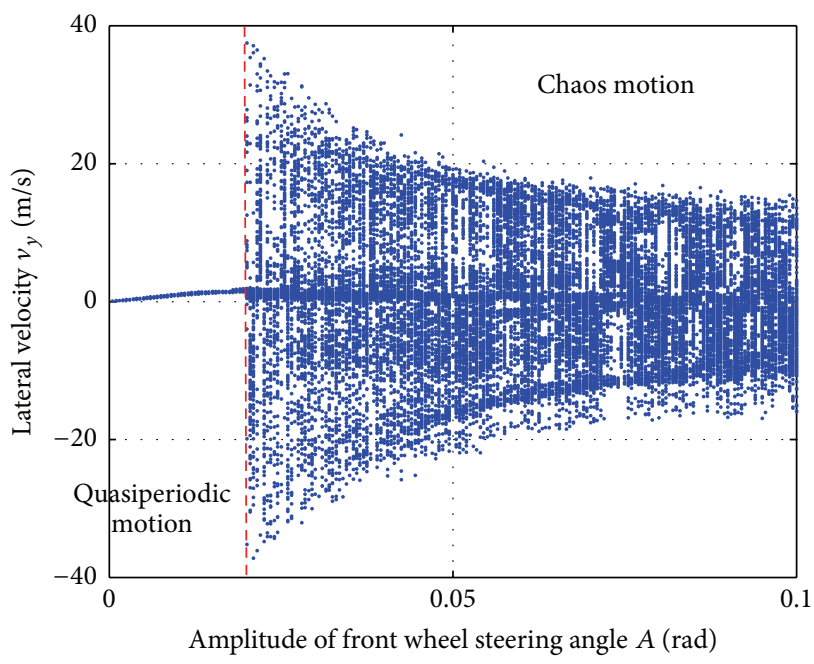

FIGURE 4: Bifurcation diagrams of $v_{y}\left(T_{d}=140 \mathrm{Nm}, v_{x}=20 \mathrm{~m} / \mathrm{s}\right.$, front-wheel-drive mode).

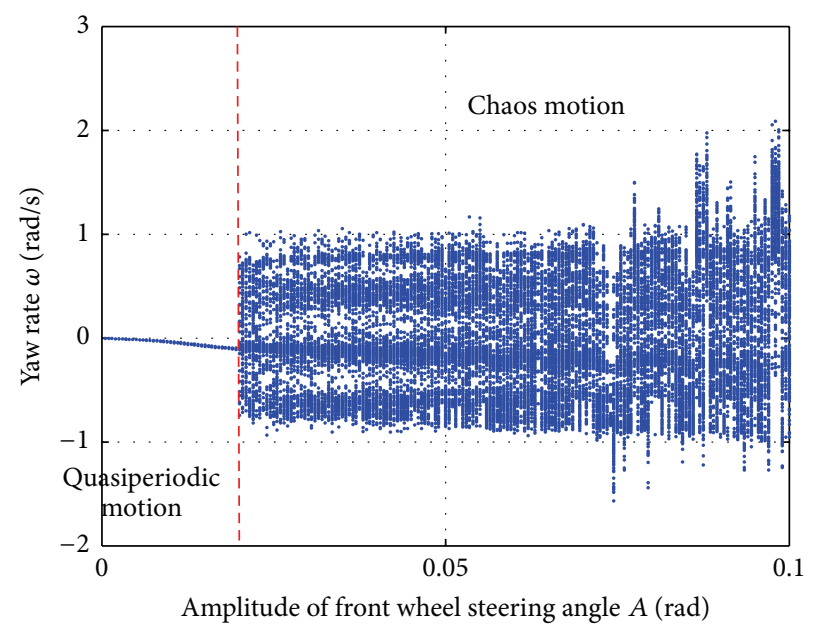

FIGURE 5: Bifurcation diagrams of $\omega\left(T_{d}=140 \mathrm{Nm}, v_{x}=20 \mathrm{~m} / \mathrm{s}\right.$, front-wheel-drive mode).

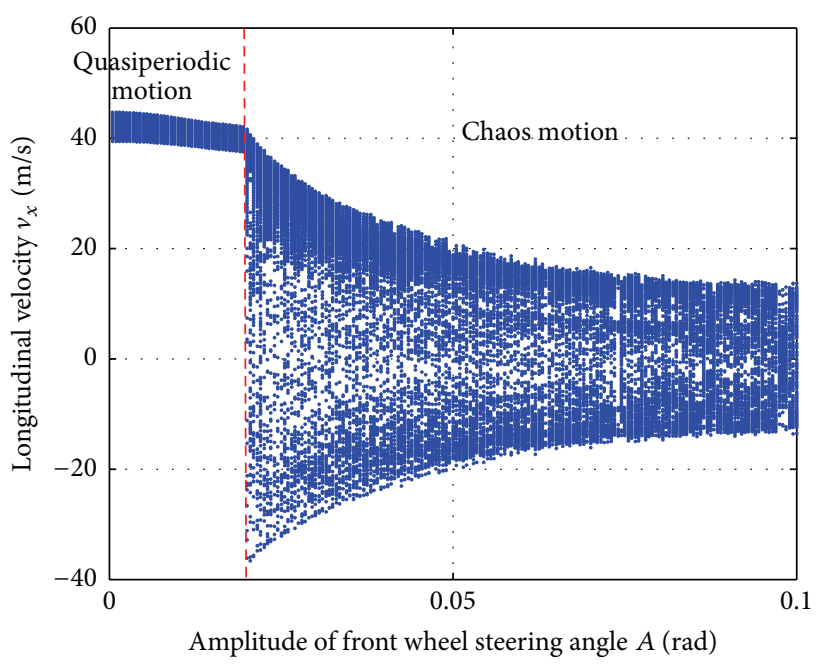

FIgURE 6: Bifurcation diagrams of $v_{x}\left(T_{d}=140 \mathrm{Nm}, v_{x}=20 \mathrm{~m} / \mathrm{s}\right.$, front-wheel-drive mode). 

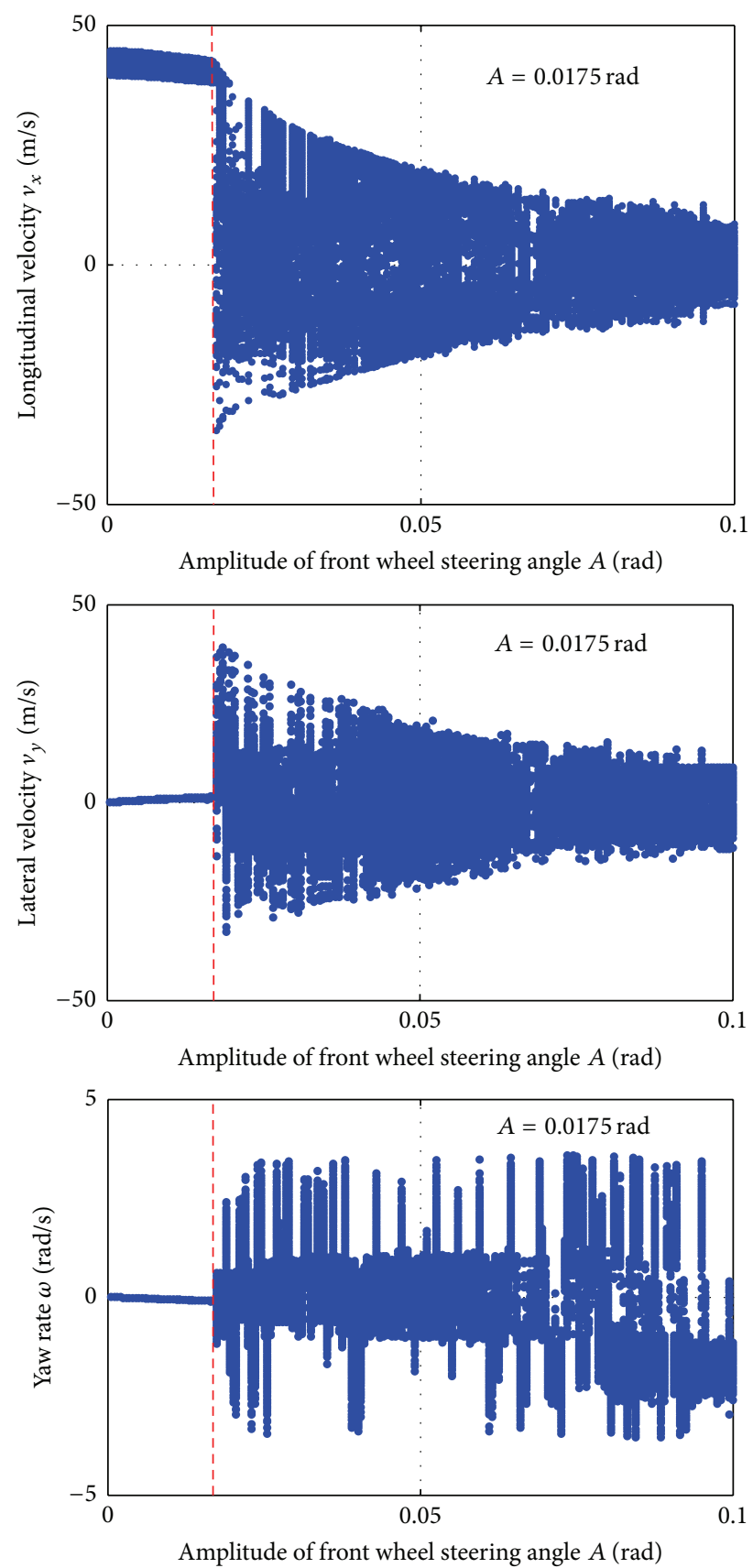

FIgURE 7: Bifurcation diagrams of $v_{y}$, $\omega$, and $v_{x}\left(T_{d}=140 \mathrm{Nm}, v_{x}=\right.$ $20 \mathrm{~m} / \mathrm{s}$, all-wheel-drive mode).

steering angle $f=0.4 \mathrm{~Hz}$. The expression of the angular frequency of front wheel steering angle is as follows:

$$
\omega_{s f}=2 \pi \cdot 0.4=0.8 \pi \text {. }
$$

Figures 4-6 show the bifurcation diagrams of three state variables $\left(v_{x}, v_{y}\right.$, and $\left.\omega\right)$ under front-wheel-drive mode.

These figures are obtained as follows. For a given value of $T_{d}$, differential system (9) is solved numerically using MATLAB, starting from a constant initial point, $v_{x}=20 \mathrm{~m} / \mathrm{s}$, $v_{y}=0 \mathrm{~m} / \mathrm{s}, \omega=0 \mathrm{rad} / \mathrm{s}, \omega_{f}=0 \mathrm{rad} / \mathrm{s}, \omega_{r}=0 \mathrm{rad} / \mathrm{s}, \delta_{f}=0$, and
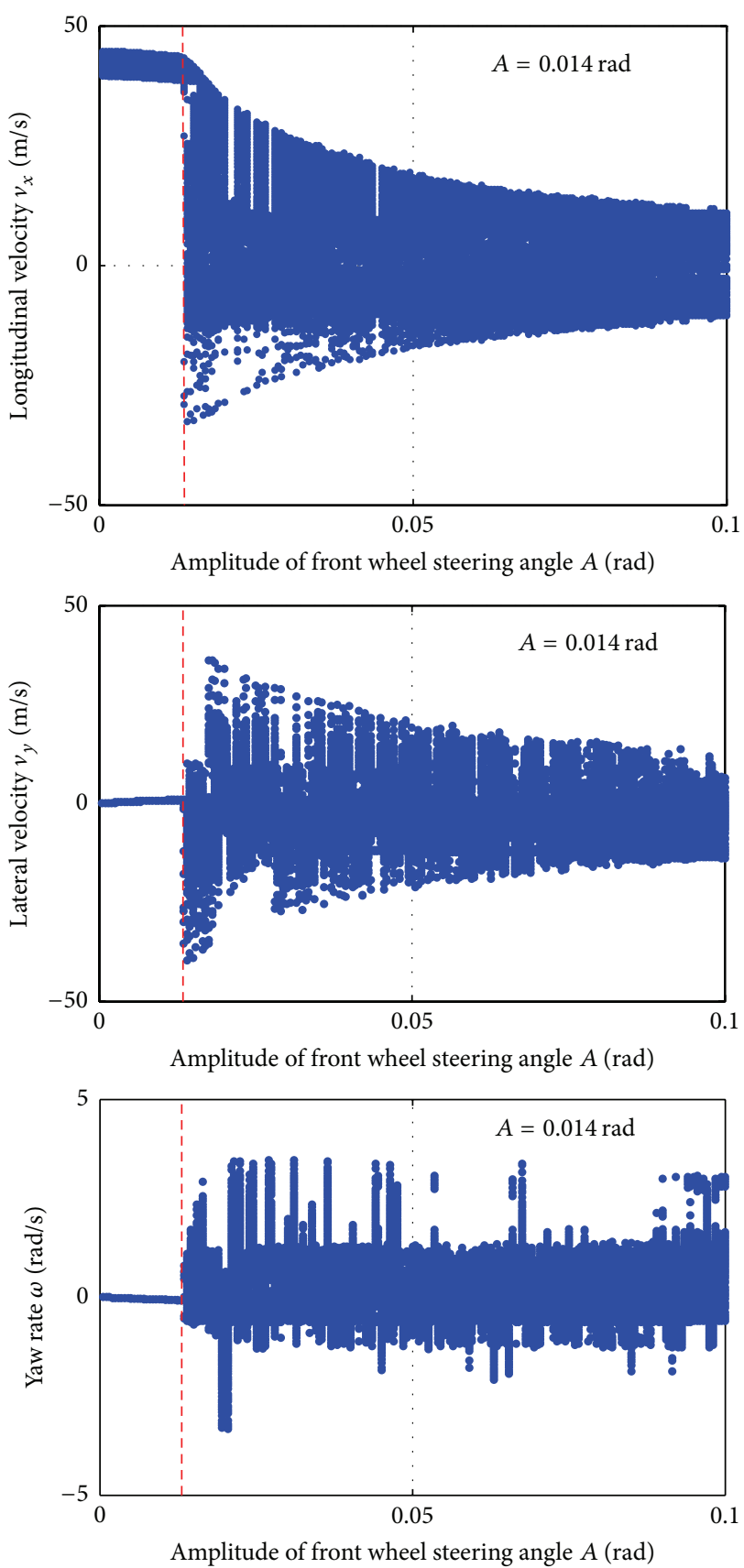

FIGURE 8: Bifurcation diagrams of $v_{y}, \omega$, and $v_{x}\left(T_{d}=140 \mathrm{Nm}, v_{x}=\right.$ $20 \mathrm{~m} / \mathrm{s}$, rear-wheel-drive mode).

$\omega_{s f}=0.8 \pi$, for $t=0$. After the transient behavior vanishes, the variables $\left(v_{x}, v_{y}, \omega, \omega_{f}\right.$, and $\left.\omega_{r}\right)$ are sampled in the range $t<500 \mathrm{~s}$ at the frequency $f=0.4 \mathrm{~Hz}$. The bifurcation diagram is composed of all the sampling points of state variables and the corresponding amplitude of front wheel steering angle $A$.

By the results of bifurcation diagram, we get the following.

(1) When the amplitude of front wheel steering angle $A<0.02 \mathrm{rad}$, the lateral velocity $v_{y}$ is gradually increasing as $A$ increases. When $A=0.0195 \mathrm{rad}, v_{y}$ varying range eventually reaches $[1.381,1.879] \mathrm{m} / \mathrm{s}$. But the yaw angular velocity is gradually decreasing with the increasing $A$. 

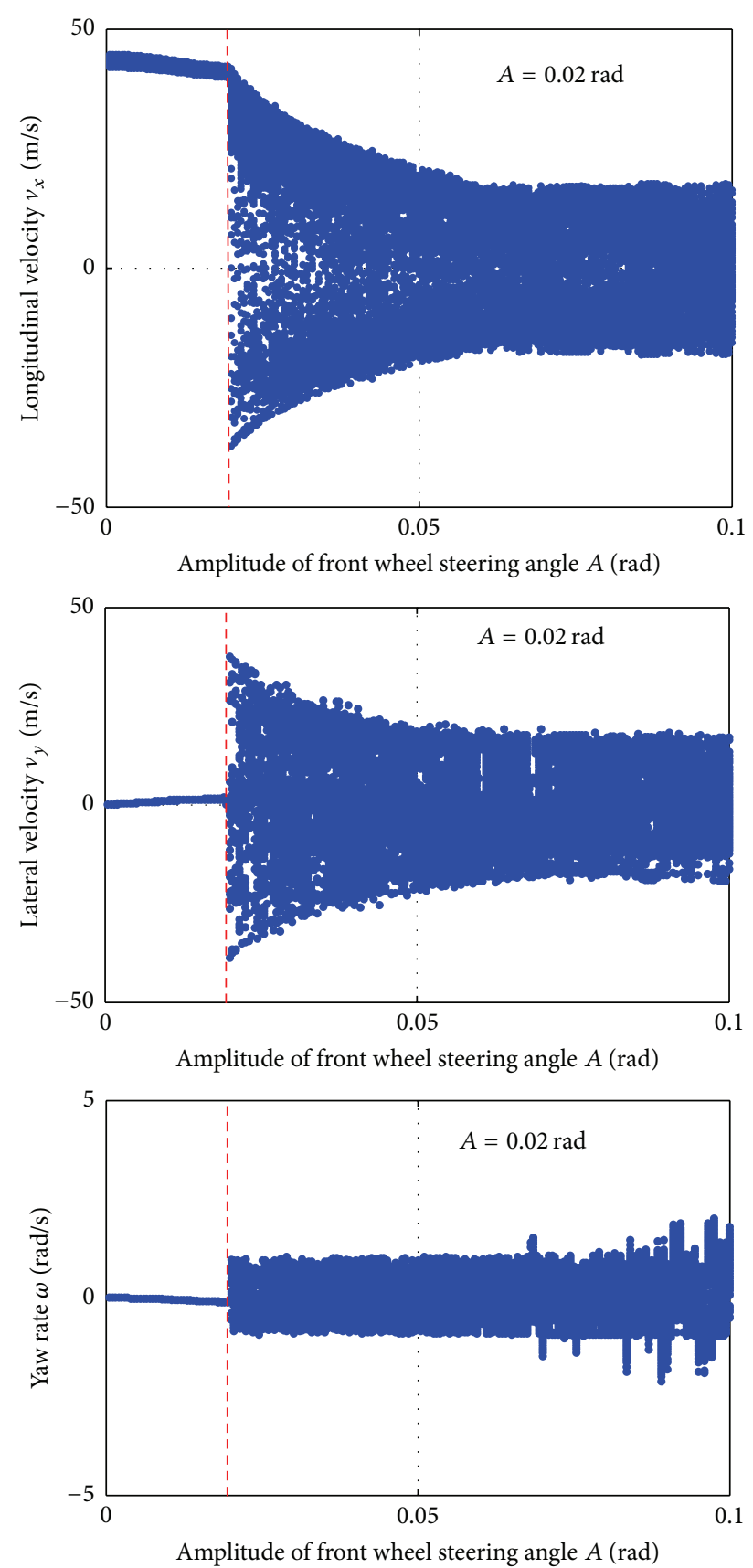

FIGURE 9: Bifurcation diagrams of $v_{y}, \omega$, and $v_{x}\left(T_{d}=140 \mathrm{Nm}, v_{x}=\right.$ $30 \mathrm{~m} / \mathrm{s}$, front-wheel-drive mode).

When $A=0.0195 \mathrm{rad}, \omega$ varying range is $[-0.1087$, $-0.09283] \mathrm{rad} / \mathrm{s}$. When driving torque $T_{d}=140 \mathrm{Nm}$, since the driving torque is greater than the air resistance, the longitudinal velocity $v_{x}$ increases. But, with the increase of $A$, when $A=0.0195 \mathrm{rad}$, the varying range of $v_{x}$ gradually reduces from $[39.47,44.71] \mathrm{m} / \mathrm{s}$ to $[37.54,42.09] \mathrm{m} / \mathrm{s}$.

(2) When the amplitude of front wheel steering angle $A=0.02 \mathrm{rad}$, the varying range of $v_{y}$ sharply increases to $[-35.21,37.53] \mathrm{m} / \mathrm{s}$. Then the varying range of $v_{y}$ decreases as $A$ increases. When $A=0.1 \mathrm{rad}$, varying range of $v_{y}$ is $[-16,14.68] \mathrm{m} / \mathrm{s}$. When $A=0.02 \mathrm{rad}$, the varying range of
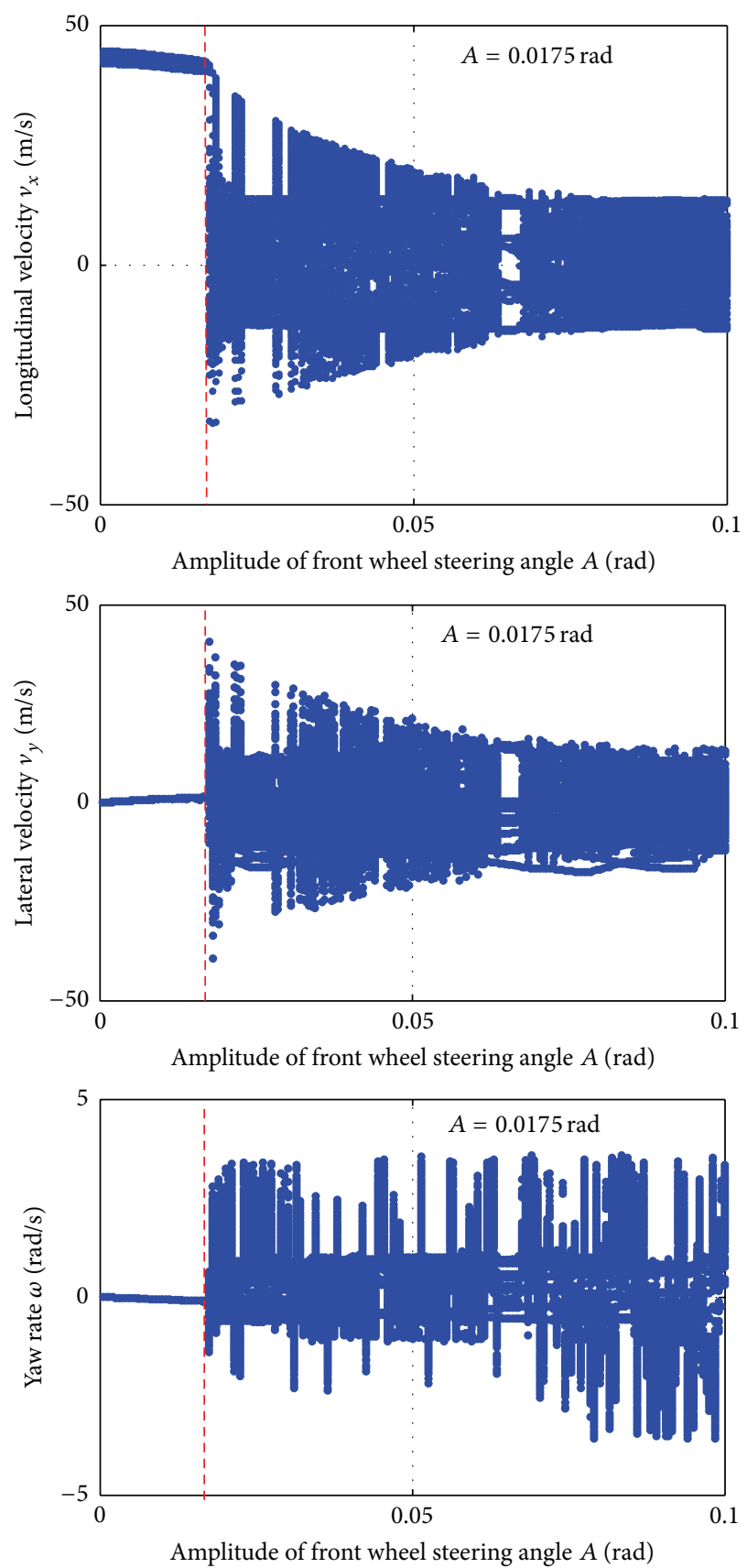

FIGURE 10: Bifurcation diagrams of $v_{y}$, $\omega$, and $v_{x}\left(T_{d}=140 \mathrm{Nm}, v_{x}=\right.$ $30 \mathrm{~m} / \mathrm{s}$, all-wheel-drive mode).

$\omega$ also sharply increases to $[-0.7432,0.7834] \mathrm{m} / \mathrm{s}$. Then the varying range of $\omega$ increases as $A$ increases. When $A=0.1 \mathrm{rad}$, the varying range of $\omega$ is $[-0.9546,1.176] \mathrm{rad} / \mathrm{s}$. When $A=$ $0.02 \mathrm{rad}$, the varying range of $v_{x}$ also sharply increases to $[-36.12,41.36] \mathrm{m} / \mathrm{s}$. Then the varying range of $v_{x}$ decreases as $A$ increases. When $A=0.1 \mathrm{rad}$, the varying range of $v_{x}$ is $[-13.54,13.71] \mathrm{m} / \mathrm{s}$.

Figure 7 is the bifurcation diagrams of three state variables $\left(v_{x}, v_{y}\right.$, and $\left.\omega\right)$ under all-wheel-drive mode. Figure 8 corresponds to rear-wheel-drive mode. 

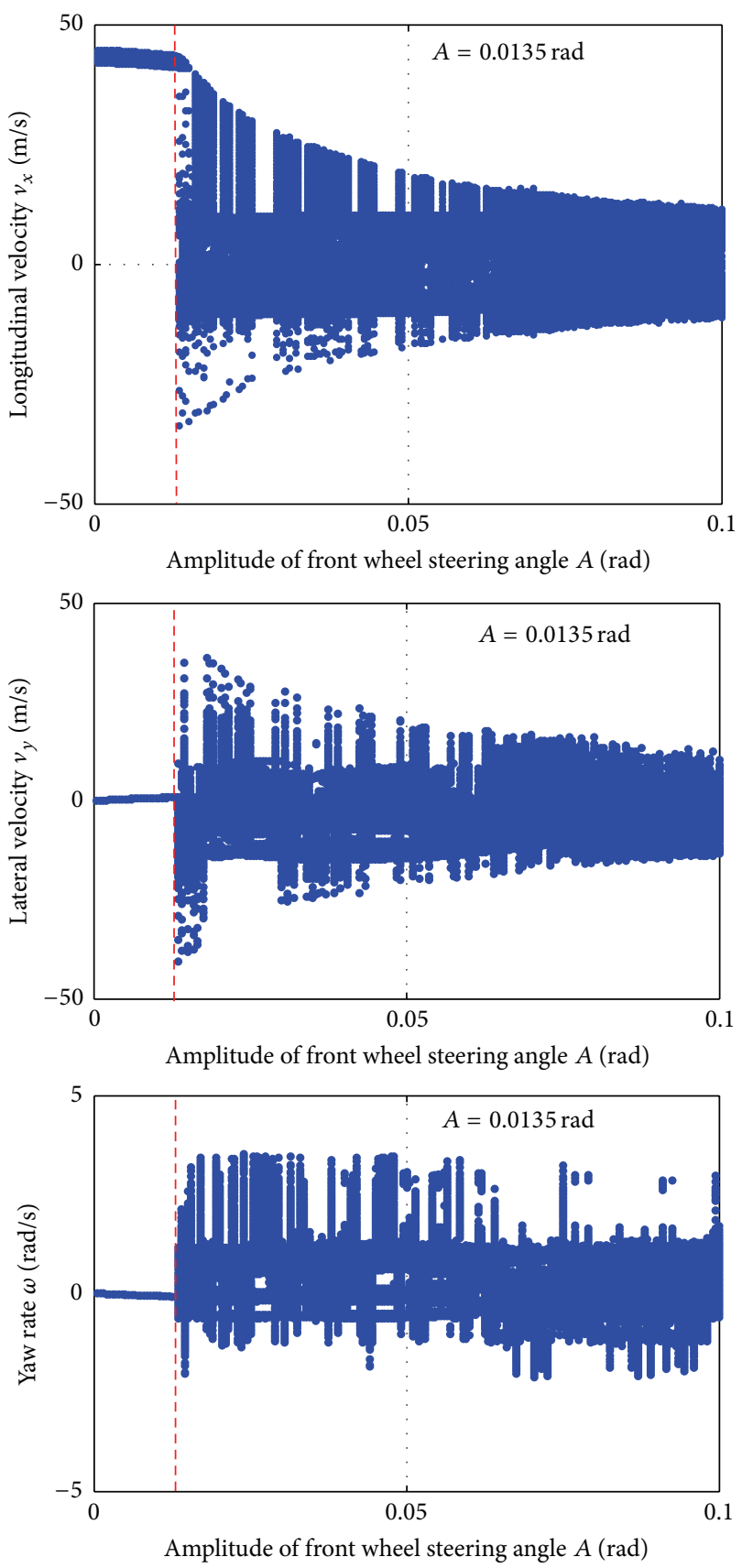

FIGURE 11: Bifurcation diagrams of $v_{y}, \omega$, and $v_{x}\left(T_{d}=140 \mathrm{Nm}, v_{x}=\right.$ $30 \mathrm{~m} / \mathrm{s}$, rear-wheel-drive mode).

It is obvious that the overall trend of the bifurcation diagrams of all-wheel-drive mode and rear-wheel-drive mode is in accordance with the bifurcation diagram of frontwheel-drive mode. The varying range of yaw rate expands to $(-4,4) \mathrm{rad} / \mathrm{s}$. But the bifurcation parameter $A$ (amplitude of front wheel steering angle) has the obvious differences under different driving mode. $A$ of front-wheel-drive mode $(A=$ $0.02 \mathrm{rad})>A$ of all-wheel-drive mode $(A=0.0175 \mathrm{rad})>$ $A$ of rear-wheel-drive mode $(A=0.014 \mathrm{rad})$. So, it can be conclude that the different driving mode has obvious effects on the bifurcation characteristics.
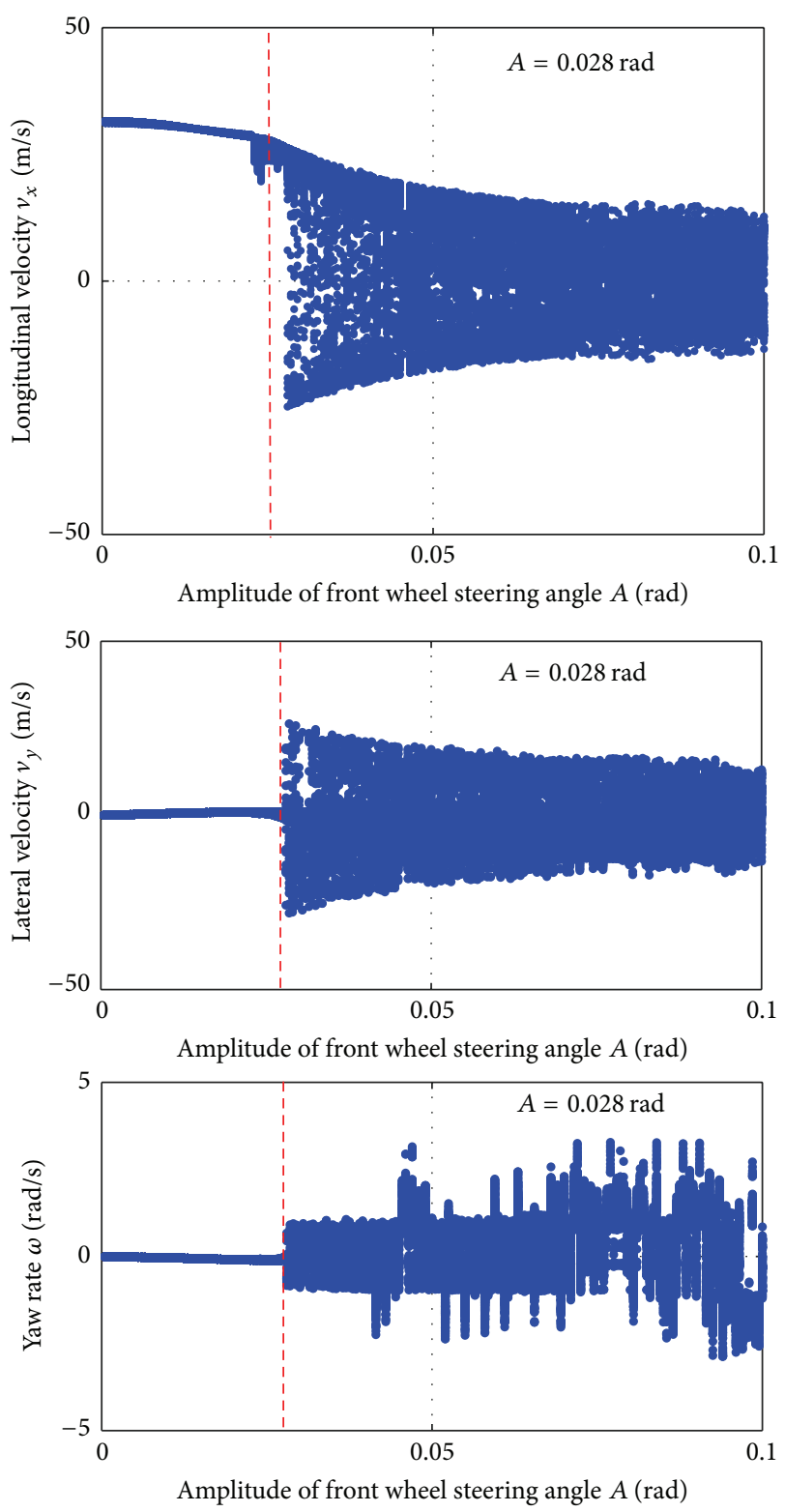

FIGURE 12: Bifurcation diagrams of $v_{y}, \omega$, and $v_{x}\left(T_{d}=70 \mathrm{Nm}, v_{x}=\right.$ $30 \mathrm{~m} / \mathrm{s}$, front-wheel-drive mode).

Figures 9-11 are the system state variable bifurcation diagrams of different driving mode with driving torque $T_{d}=$ $140 \mathrm{Nm}$ and initial longitudinal velocity $v_{x}=30 \mathrm{~m} / \mathrm{s}$.

It is clear that the overall trend of the bifurcation diagrams is in accordance with the bifurcation diagram of initial longitudinal velocity $v_{x}=20 \mathrm{~m} / \mathrm{s}$. The bifurcation parameter $A$ varies a little when the initial longitudinal velocity increases to $v_{x}=30 \mathrm{~m} / \mathrm{s}$. The bifurcation parameter of front-wheeldrive mode is still $A=0.02 \mathrm{rad}$. The bifurcation parameter of all-wheel-drive mode is $A=0.0175 \mathrm{rad}$ as before. But the bifurcation parameter of rear-wheel-drive mode decreases to $A=0.0135 \mathrm{rad}$. There is no sort order change of $A$ under different driving mode. $A$ of front-wheel-drive mode $(A=$ $0.02 \mathrm{rad})>A$ of all-wheel-drive mode $(A=0.0175 \mathrm{rad})>A$ of rear-wheel-drive mode $(A=0.0135 \mathrm{rad})$. 

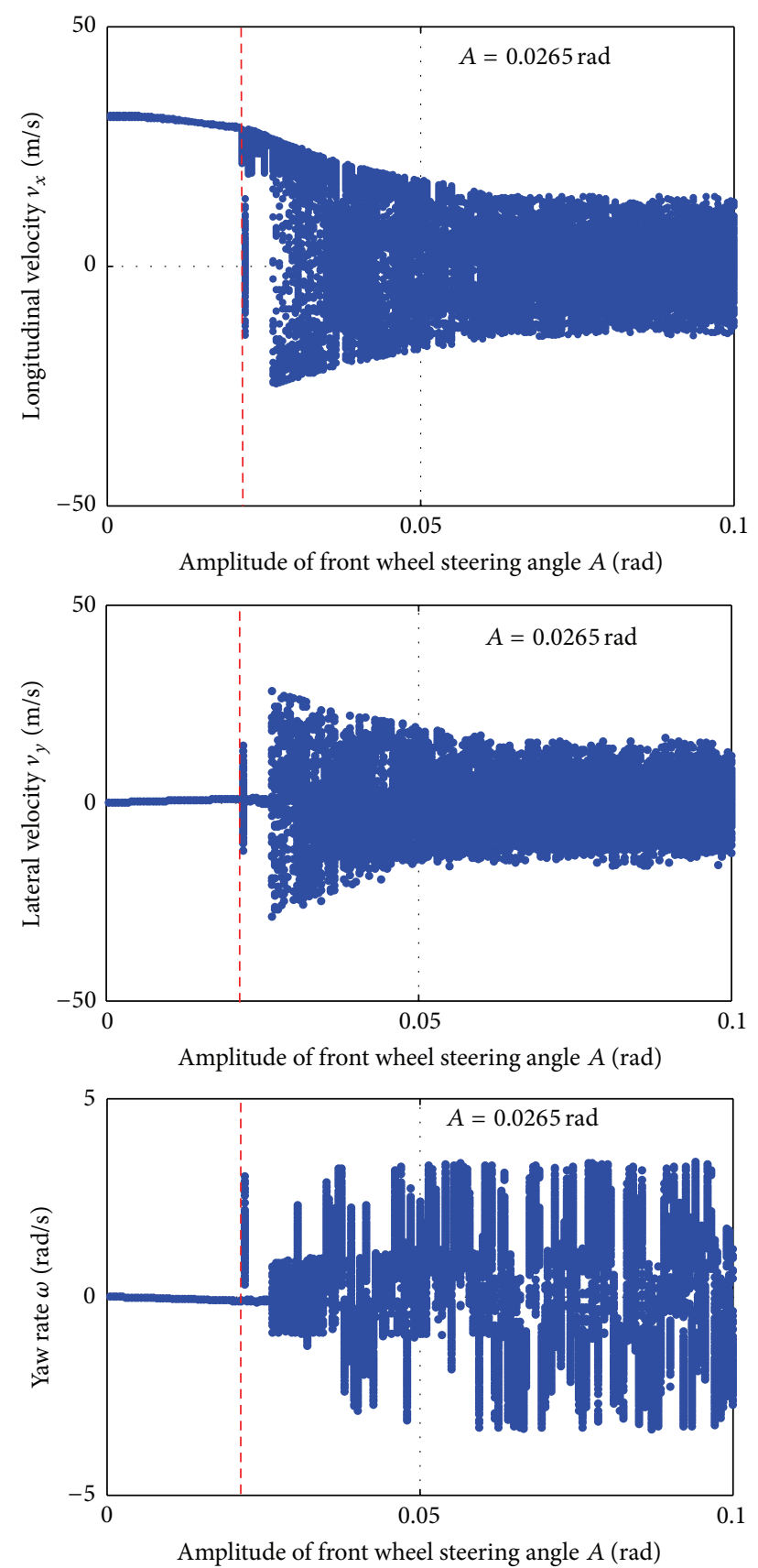

FIGURE 13: Bifurcation diagrams of $v_{y}$, $\omega$, and $v_{x}\left(T_{d}=70 \mathrm{Nm}, v_{x}=\right.$ $30 \mathrm{~m} / \mathrm{s}$, all-wheel-drive mode).

Figures 12-14 are the system state variable bifurcation diagrams of different driving mode with driving torque $T_{d}=$ $70 \mathrm{Nm}$ and initial longitudinal velocity $v_{x}=30 \mathrm{~m} / \mathrm{s}$.

It is clear that the overall trend of the bifurcation diagrams is in accordance with the previous bifurcation diagrams. The bifurcation parameter $A$ varies a lot when the driving torque reduces to $T_{d}=70 \mathrm{Nm}$. The bifurcation parameter of frontwheel-drive mode increases to $A=0.028 \mathrm{rad}$. The bifurcation parameter of all-wheel-drive mode is $A=0.0265 \mathrm{rad}$. The bifurcation parameter of rear-wheel-drive mode is
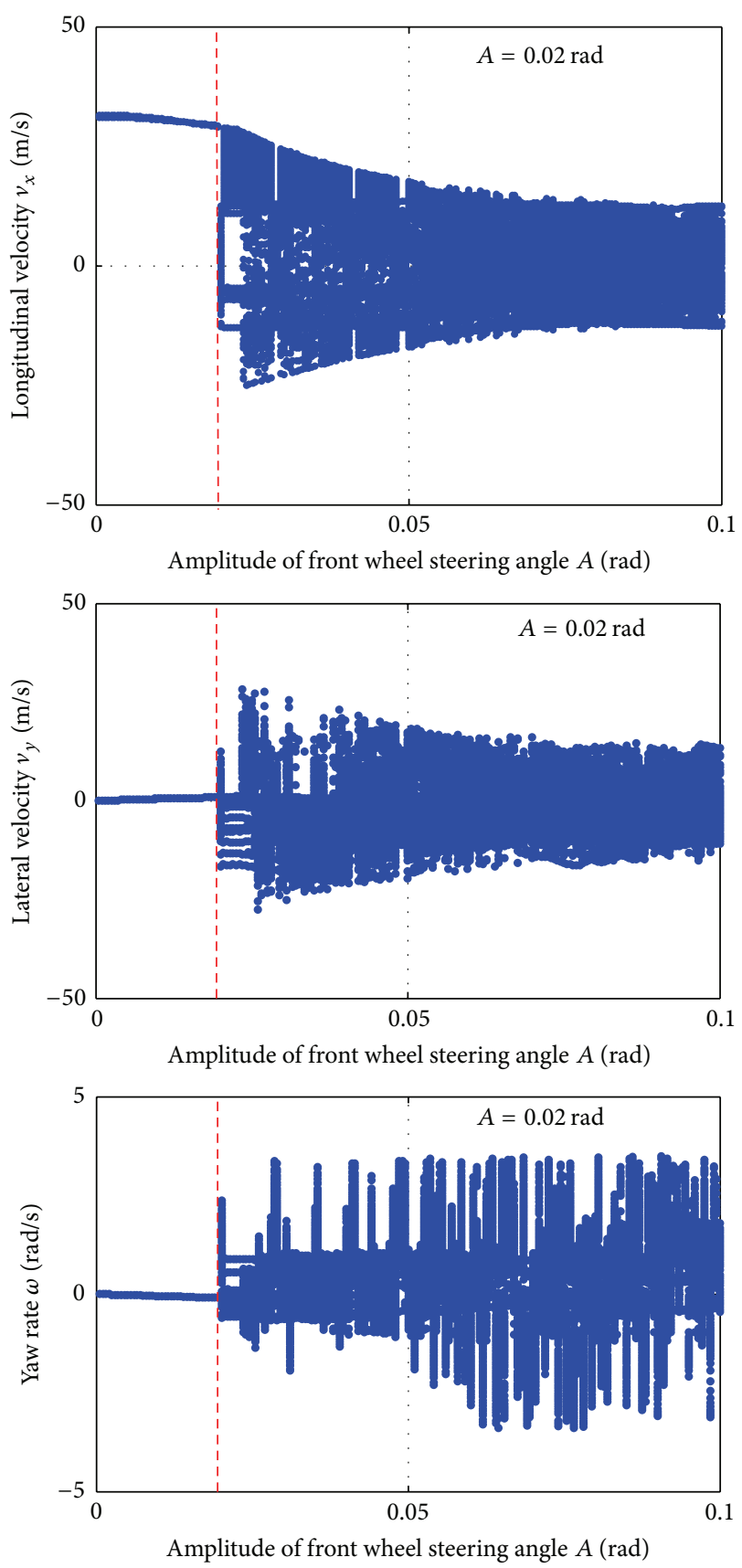

FIgURE 14: Bifurcation diagrams of $v_{y}$, $\omega$, and $v_{x}\left(T_{d}=70 \mathrm{Nm}, v_{x}=\right.$ $30 \mathrm{~m} / \mathrm{s}$, rear-wheel-drive mode).

$A=0.02 \mathrm{rad}$. There is no sort order change of $A$ under different driving mode. $A$ of front-wheel-drive mode $(A=$ $0.028 \mathrm{rad})>A$ of all-wheel-drive mode $(A=0.0265 \mathrm{rad})>A$ of rear-wheel-drive mode ( $A=0.02 \mathrm{rad}$ ).

\section{Dynamic Evolution Process of Steering and Driving Bifurcation}

In fact, the system state variables bifurcation diagrams in previous section indicate that the $5 \mathrm{DOF}$ vehicle system dynamic 


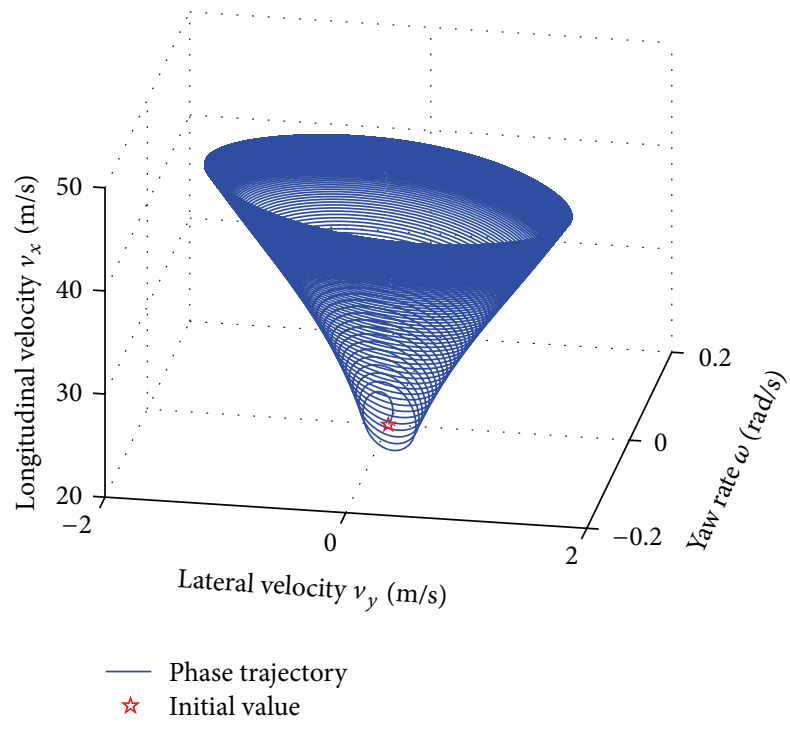

FIGURE 15: $v_{x}-v_{y}-\omega$ phase space trajectories $(A=0.015 \mathrm{rad}$, frontwheel-drive mode).

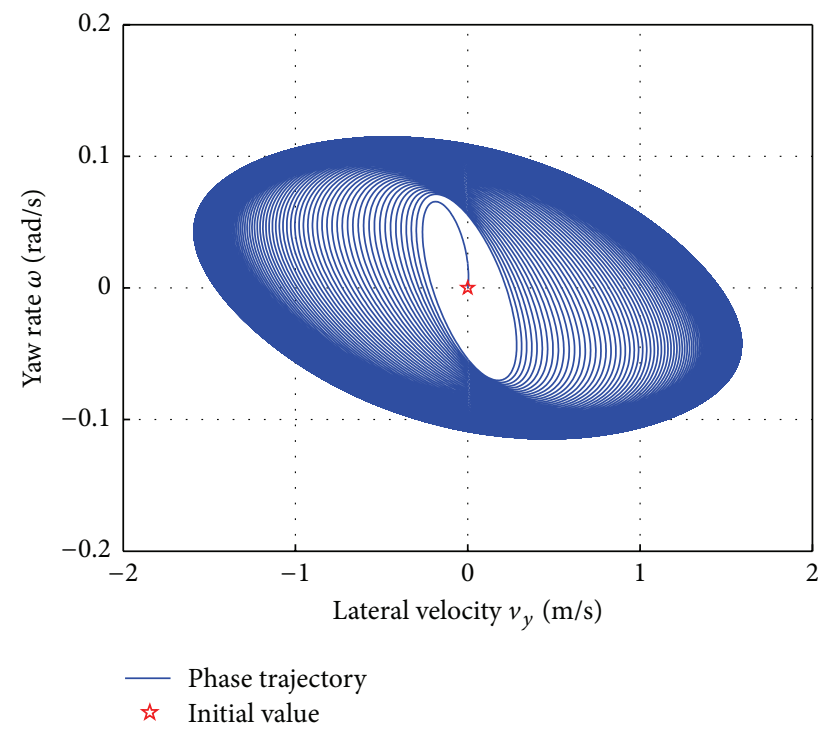

FIGURE 16: $v_{x}-v_{y}-\omega$ phase space portrait onto $v_{y}-\omega$ plane $(A=$ $0.015 \mathrm{rad}$, front-wheel-drive mode).

characteristics are the typical chaotic motion. Namely, the $5 \mathrm{DOF}$ vehicle system turns into the chaotic motion from the quasiperiodic motion with the constant driving torque and periodic front wheel steering angle input. In this section, the details of the dynamic evolution process of steering and driving bifurcation are confirmed.

Taking the front-wheel-drive mode as an example, the simulations are carried out in this section. The simulation condition is identified with previous section, namely, the steering and driving simulations under constant driving torque.
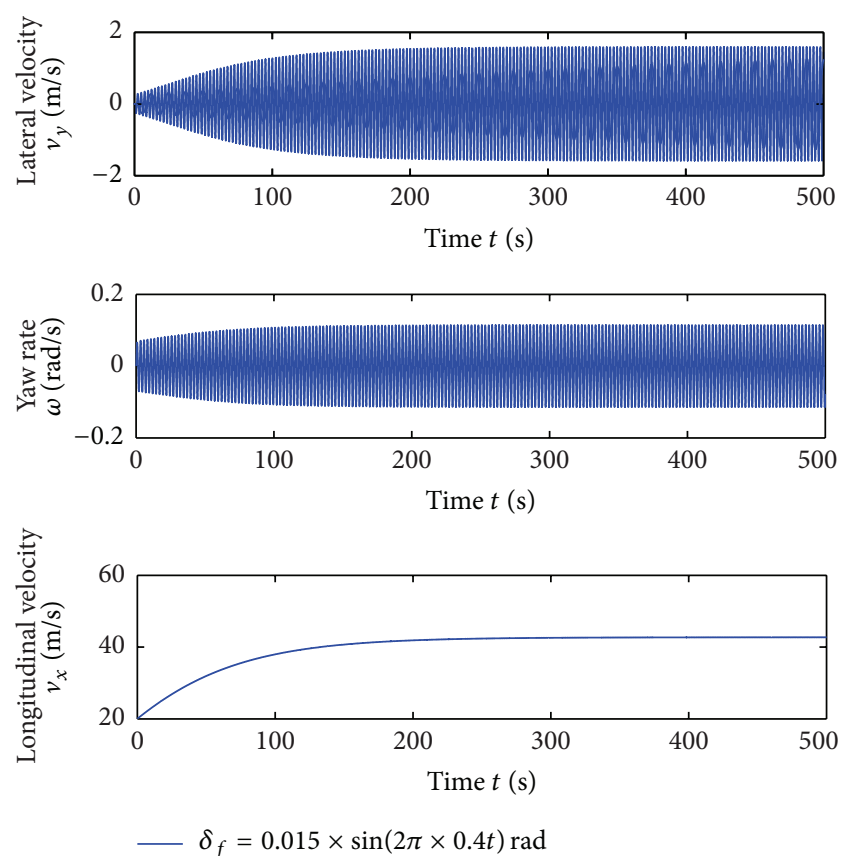

FIGURE 17: State variables ( $A=0.015 \mathrm{rad}$, front-wheel-drive mode $)$.
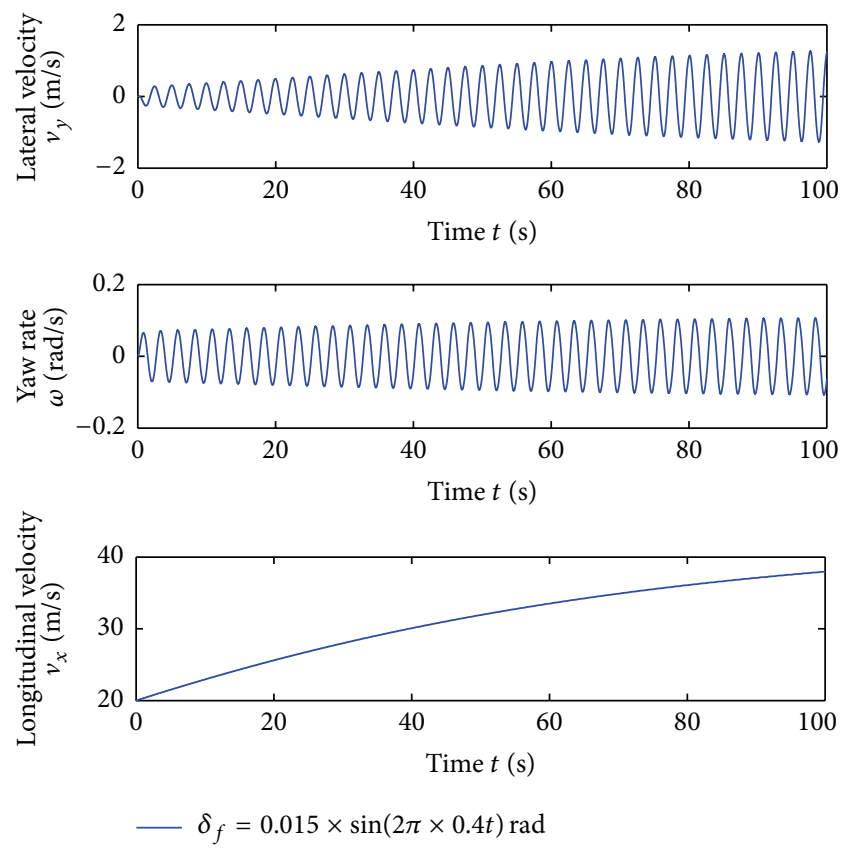

FIGURE 18: Part of state variables sequence $(A=0.015$ rad, frontwheel-drive mode).

For the specific simulation parameters, we get the following.

The initial simulation values include $v_{x}=20 \mathrm{~m} / \mathrm{s}, v_{y}=$ $0 \mathrm{~m} / \mathrm{s}, \omega=0 \mathrm{rad} / \mathrm{s}, \omega_{f}=0 \mathrm{rad} / \mathrm{s}$, and $\omega_{r}=0 \mathrm{rad} / \mathrm{s}$. The constant driving torque $T_{d}=140 \mathrm{Nm}$. The driving mode is front-wheeldrive one. The amplitudes of front wheel steering angle are $A=0.015 \mathrm{rad}, A=0.02 \mathrm{rad}$, and $A=0.04 \mathrm{rad}$. The frequency 

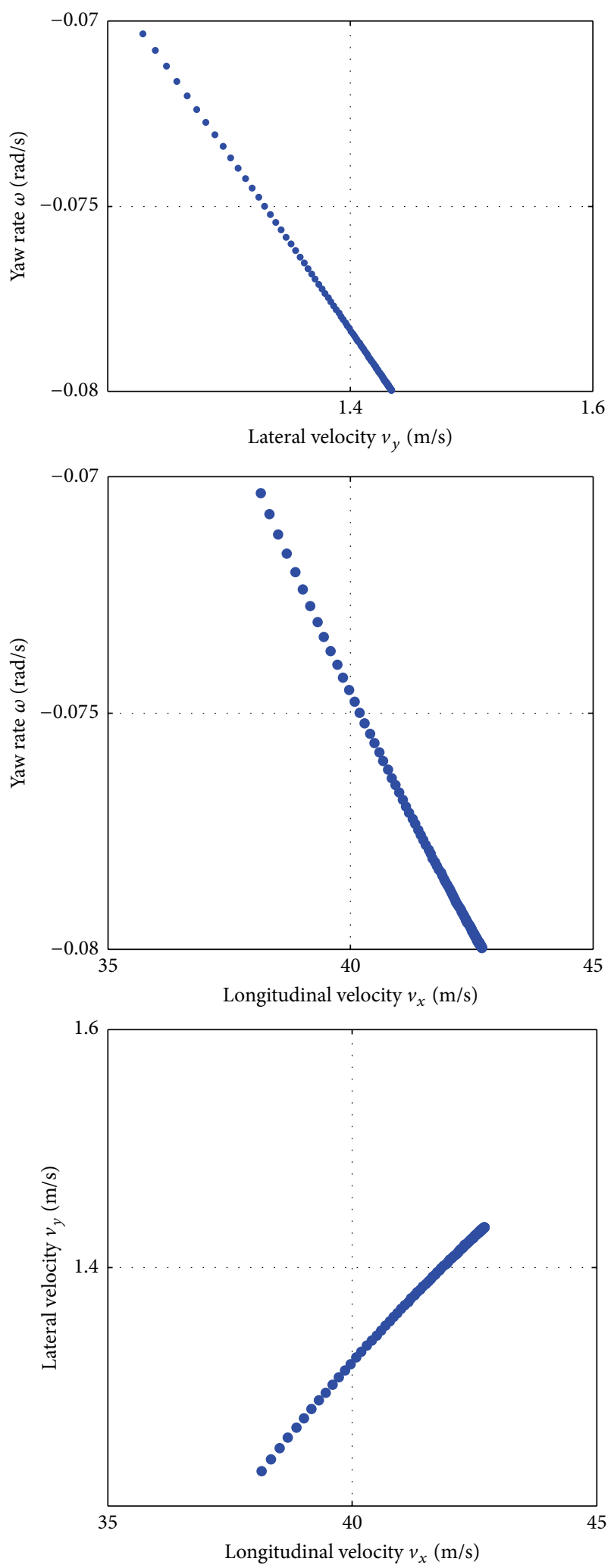

FIGURE 19: Poincare section of phase trajectory $(A=0.015 \mathrm{rad}$, front-wheel-drive mode).

of front wheel steering angle $f=0.4 \mathrm{~Hz}$. The expression of the angular frequency of front wheel steering angle is still (10).
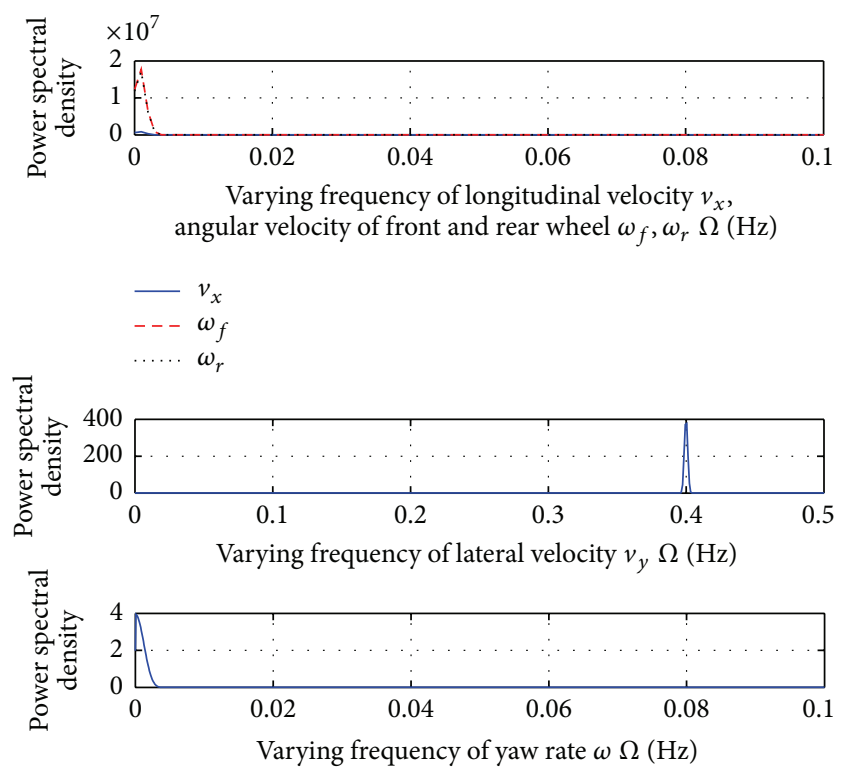

FIGURE 20: Power spectral density of state variables $(A=0.015 \mathrm{rad}$, front-wheel-drive mode).

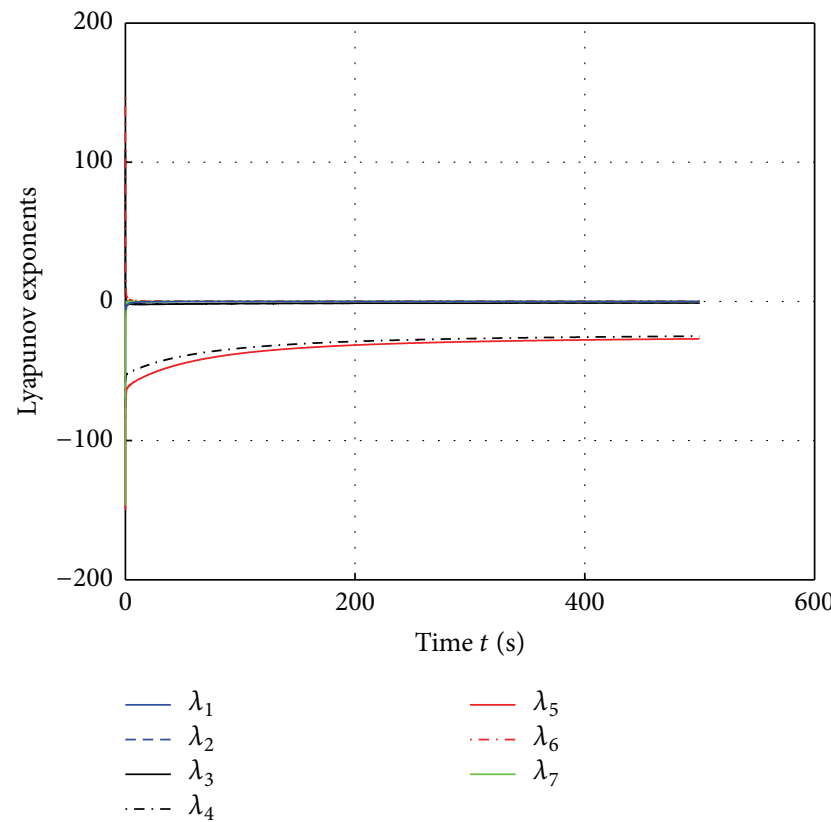

FIGURE 21: Lyapunov exponents $(A=0.015 \mathrm{rad}$, front-wheel-drive mode).

4.1. Amplitude of Front Wheel Steering Angle $A=0.015 \mathrm{rad}$. Figures 15-22 are the numerical results with $A=0.015 \mathrm{rad}$.

Figure 15 is $v_{x}-v_{y}-\omega$ phase space trajectories.

Figure 16 is phase space trajectories in Figure 15 onto $v_{y^{-}}$ $\omega$ plane. It is shown that when $A=0.015 \mathrm{rad}$, the phase space trajectories are quasiperiodic torus. In the whole simulation period, the initial longitudinal velocity $v_{x}$ increases gradually and stabilizes in a certain range, while the lateral velocity $v_{y}$ and yaw rate $\omega$ gradually transformed into stable periodic oscillation. 


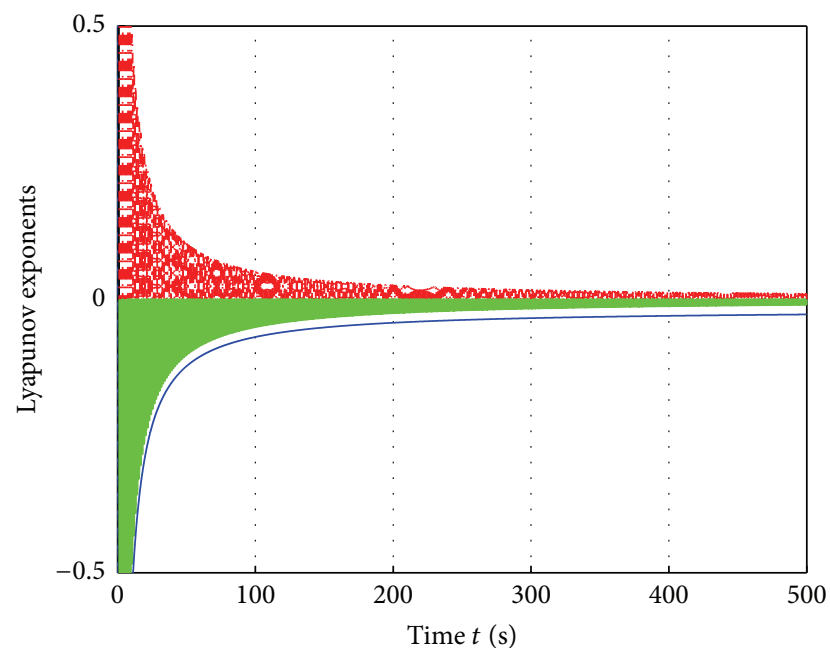

FIGURE 22: Lyapunov exponents $(A=0.015 \mathrm{rad}$, front-wheel-drive mode).

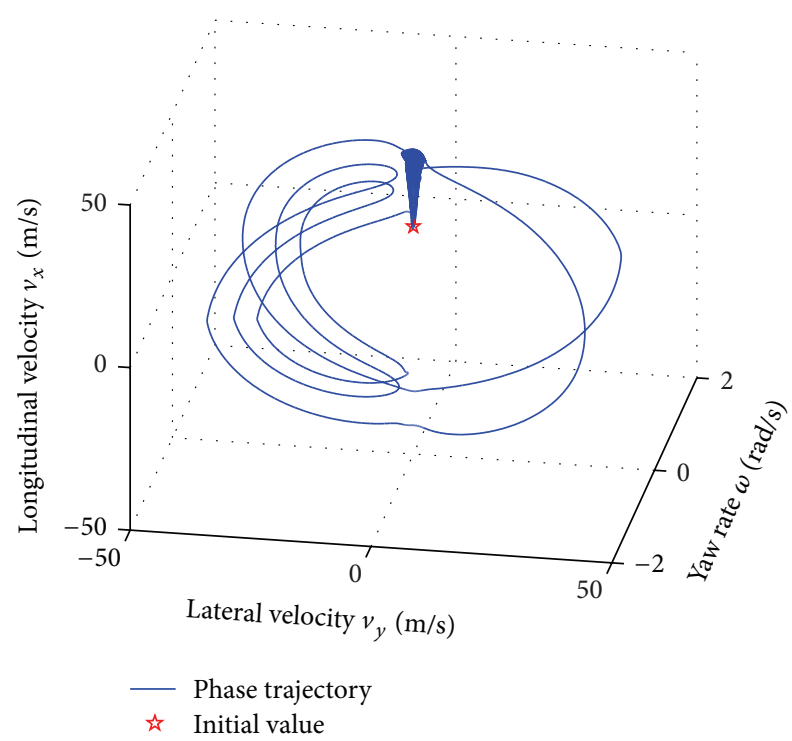

FIGURE 23: $v_{x}-v_{y}-\omega$ phase space trajectories $(A=0.02 \mathrm{rad}$, frontwheel-drive mode).

By analyzing the state variables $v_{x}, v_{y}$, and $\omega$ in Figures 17 and 18 , the same conclusion can be drawn too. Figure 18 is the calculation result in first $100 \mathrm{~s}$.

Figure 19 is the Poincare section of phase trajectory captured in period of front wheel steering angle. It can be seen that each state variable is in a straight line. This is the typical characteristics of the periodic motion.

Figure 20 is the power spectral density diagram of each state variable. In this figure, all state variables are in typical periodic motion; namely, the power spectral density shows single peak distribution characteristics. Note that the varying frequency of $v_{y}$ is consistent with the frequency of front wheel steering angle. They are both $0.4 \mathrm{~Hz}$.

Figures 21 and 22 show the Lyapunov exponents of state variables. Figure 22 is the local enlargement of Figure 21.

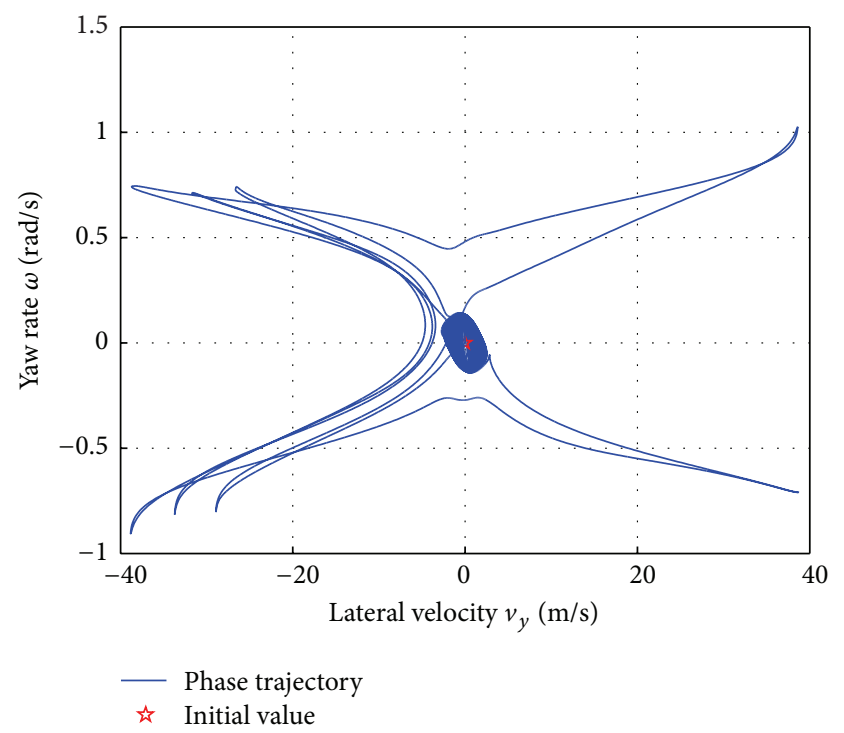

FIGURE 24: $v_{x}-v_{y}-\omega$ phase space portrait onto $v_{y}-\omega$ plane $(A=$ $0.02 \mathrm{rad}$, front-wheel-drive mode).
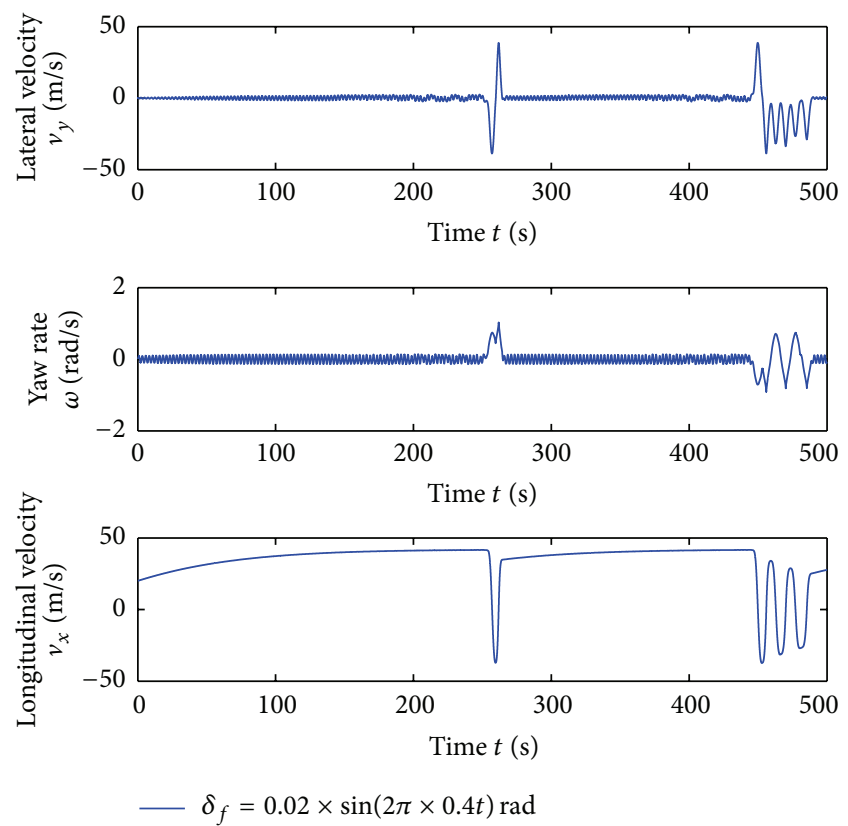

FIgURE 25: State variables ( $A=0.02 \mathrm{rad}$, front-wheel-drive mode).

The algorithm employed in this work for determining Lyapunov exponents was proposed by Wolf et al. [16]. The Lyapunov spectra are $(0,0,0,-,-,-,-)$, which prove that the system is not chaotic.

4.2. Amplitude of Front Wheel Steering Angle $A=0.02 \mathrm{rad}$. Figures 23-30 are the numerical results with $A=0.02 \mathrm{rad}$. From the previous analysis, it is known that the system bifurcation occurs.

Figures 23 and 24 are $v_{x}-v_{y}-\omega$ phase space trajectories. Compared with phase space trajectories, while $A=0.015 \mathrm{rad}$, the phase space trajectories transform into bounded chaos. 

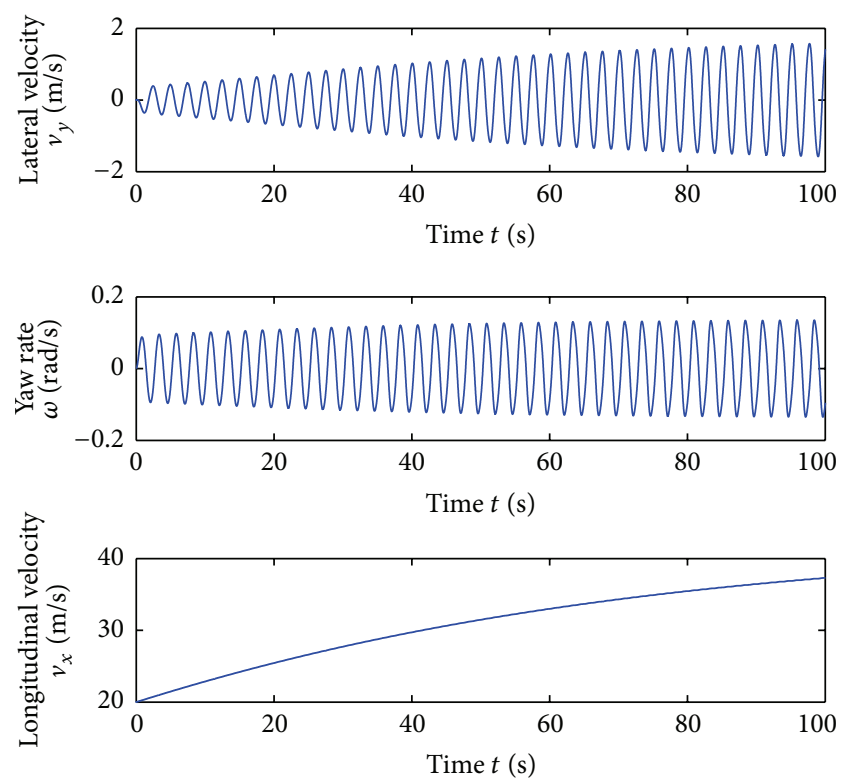

$-\delta_{f}=0.02 \times \sin (2 \pi \times 0.4 t) \mathrm{rad}$

Figure 26: Part of state variables sequence $(A=0.02 \mathrm{rad}$, frontwheel-drive mode).

By the state variables $v_{x}, v_{y}$, and $\omega$ in Figures 25 and 26, it can be concluded that, at the beginning of the simulation, the absolute value of longitudinal velocity $v_{x}$ increases gradually and stabilizes in a certain range. The absolute value of lateral velocity $v_{y}$ and yaw rate $\omega$ increases gradually and then begins to swing within a certain range. But when the simulation time at about $t=251 \mathrm{~s}$ (at this moment, the $v_{x}=38.16 \mathrm{~m} / \mathrm{s}, \omega=$ $0.1383 \mathrm{rad} / \mathrm{s}, v_{y}=-1.083 \mathrm{~m} / \mathrm{s}$ ), the first dramatic changes of system dynamic state suddenly take place.

(1) The lateral velocity decreases quickly at the beginning and then begins to increase rapidly. At $t=257 \mathrm{~s}$, lateral velocity reaches the minimum $v_{y}=-38.72 \mathrm{~m} / \mathrm{s}$. When $t=$ $261.8 \mathrm{~s}$, lateral velocity increased to $v_{y}=38.54 \mathrm{~m} / \mathrm{s}$. When $t$ $=264.5 \mathrm{~s}$ lateral speed turns back to the post scope.

(2) At the beginning, yaw rate begins to rapidly increase and then decreases rapidly, after that increases rapidly again, and finally returns to the initial state range. At $t=257 \mathrm{~s}$, yaw rate reaches the peak $\omega=0.742 \mathrm{rad} / \mathrm{s}$. At $t=259.6 \mathrm{~s}$ yaw rate reduces to $\omega=0.4464 \mathrm{rad} / \mathrm{s}$. When $t=261.8 \mathrm{~s}$, yaw rate reaches the peak again $\omega=1.026 \mathrm{rad} / \mathrm{s}$. At $t=265 \mathrm{~s}$ yaw rate turns back to the initial state range.

(3) The longitudinal velocity begins to decrease rapidly firstly, then increases rapidly, and finally stabilizes within the original scope. When $t=259.5 \mathrm{~s}$, longitudinal velocity reaches the minimum $v_{x}=-37.22 \mathrm{~m} / \mathrm{s}$. When $t=264 \mathrm{~s}$, longitudinal velocity increases to $v_{x}=34.51 \mathrm{~m} / \mathrm{s}$. After that, the longitudinal velocity increases slowly.

When the simulation time at about $t=446 \mathrm{~s}$ (at this moment, the $v_{x}=41.5 \mathrm{~m} / \mathrm{s}, \omega=-0.05763 \mathrm{rad} / \mathrm{s}, v_{y}=$ $2.843 \mathrm{~m} / \mathrm{s}$ ), system dynamic state suddenly shows second dramatic change.

(1) The lateral velocity begins to rapidly increase and then decreases quickly. When $t=449.8 \mathrm{~s}$, the lateral velocity
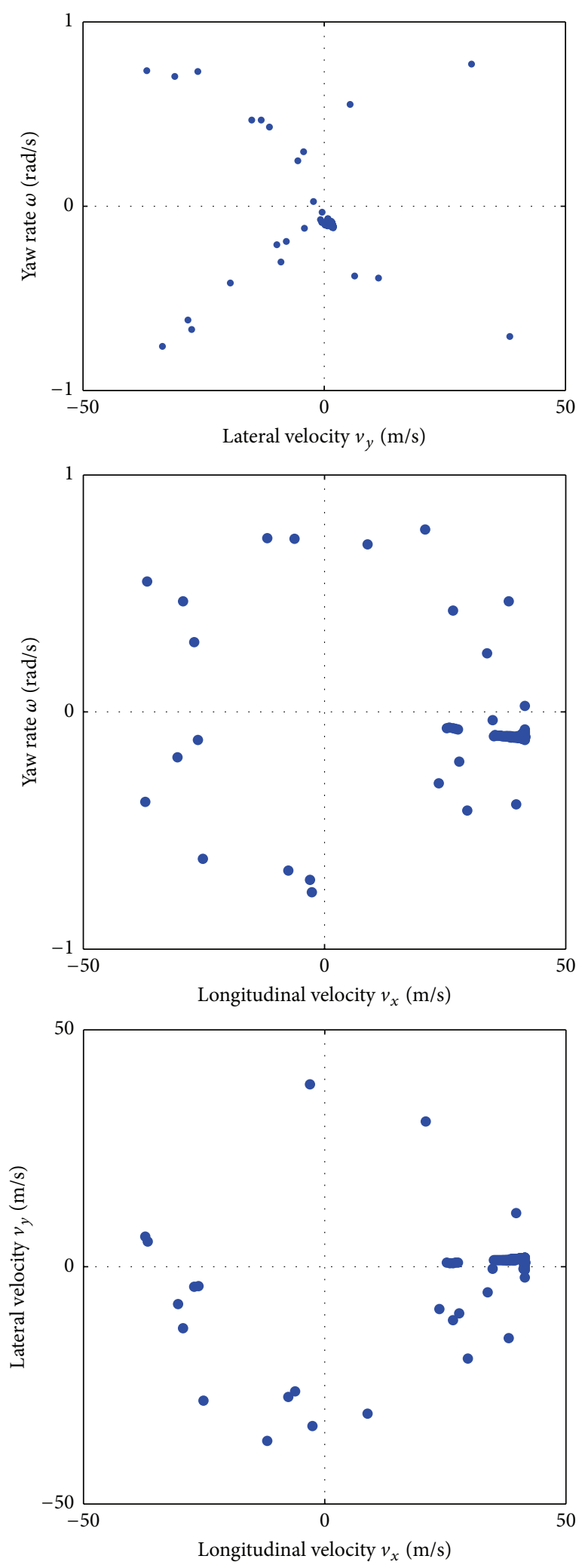

FIGURE 27: Poincare section of phase trajectory $(A=0.02$ rad, frontwheel-drive mode).

increases to $v_{y}=38.71 \mathrm{~m} / \mathrm{s}$. When $t=456 \mathrm{~s}$, lateral velocity quickly reduces to $v_{y}=-38.82 \mathrm{~m} / \mathrm{s}$. Then after vibrating 

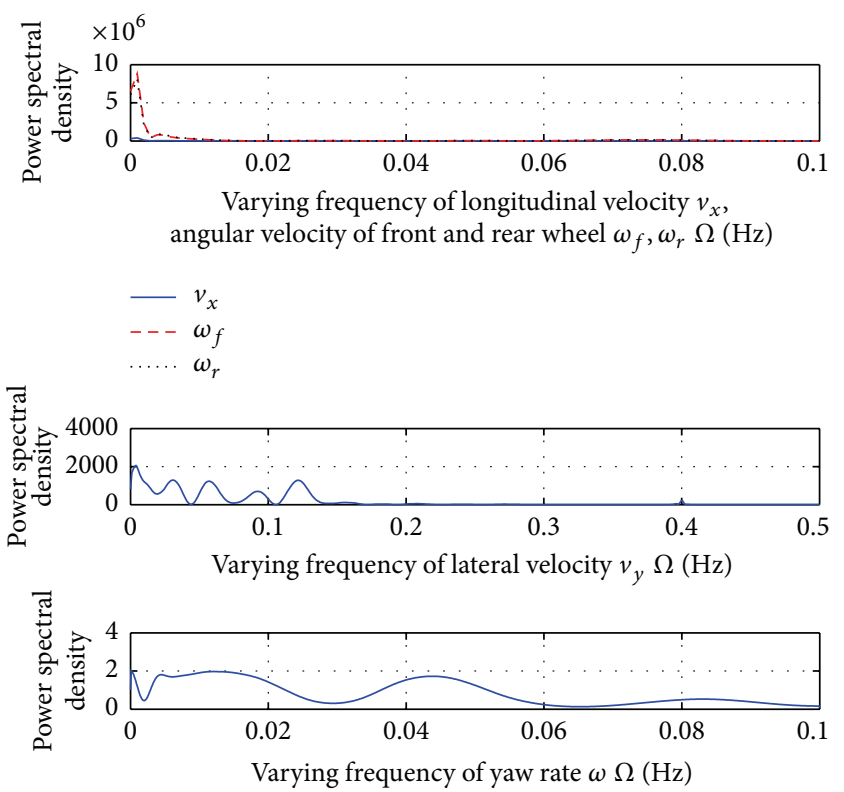

FIgURE 28: Power spectral density of state variables $(A=0.02 \mathrm{rad}$, front-wheel-drive mode).

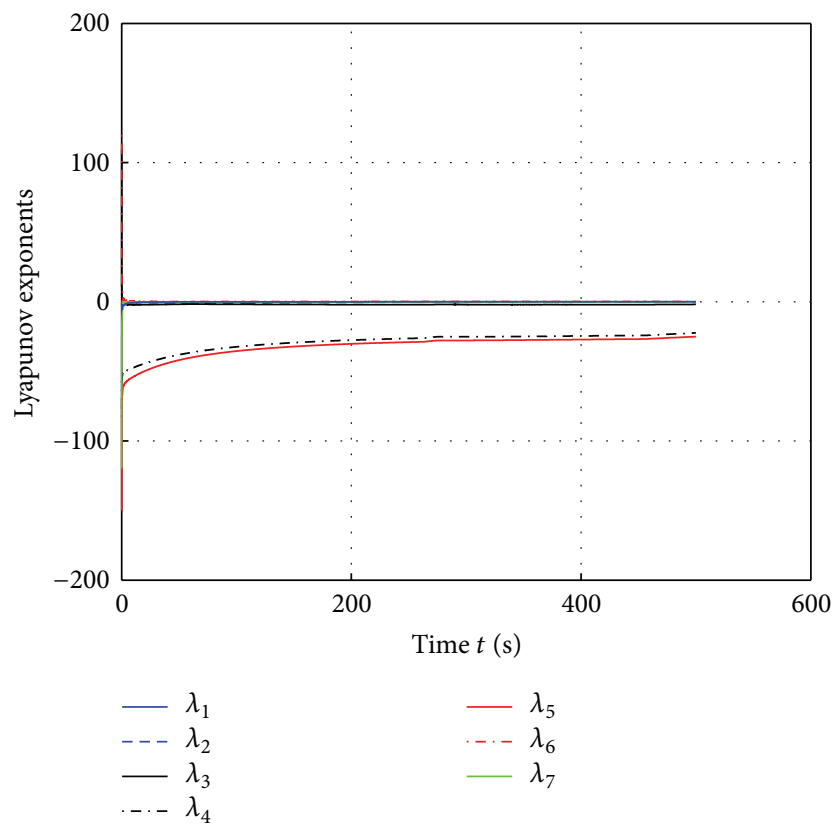

FIGURE 29: Lyapunov exponents $(A=0.02 \mathrm{rad}$, front-wheel-drive mode).

many times within negative scope, lateral velocity eventually stabilizes within the original domain at $t=490 \mathrm{~s}$.

(2) The yaw rate shows repeated oscillation at first and eventually returns to the initial state scope. When $t=449.7 \mathrm{~s}$, yaw rate reaches $\omega=-0.7104 \mathrm{rad} / \mathrm{s}$. When $t=453.4 \mathrm{~s}$, yaw rate increases to $\omega=-0.2618 \mathrm{rad} / \mathrm{s}$. Yaw rate reaches its peak at $t=456 \mathrm{~s}, \omega=-0.9067 \mathrm{rad} / \mathrm{s}$. Then the continuous repeated vibrations occur. The maximum yaw rate reaches $\omega=0.7415 \mathrm{rad} / \mathrm{s}$ at $t=477.3 \mathrm{~s}$. And the minimum value

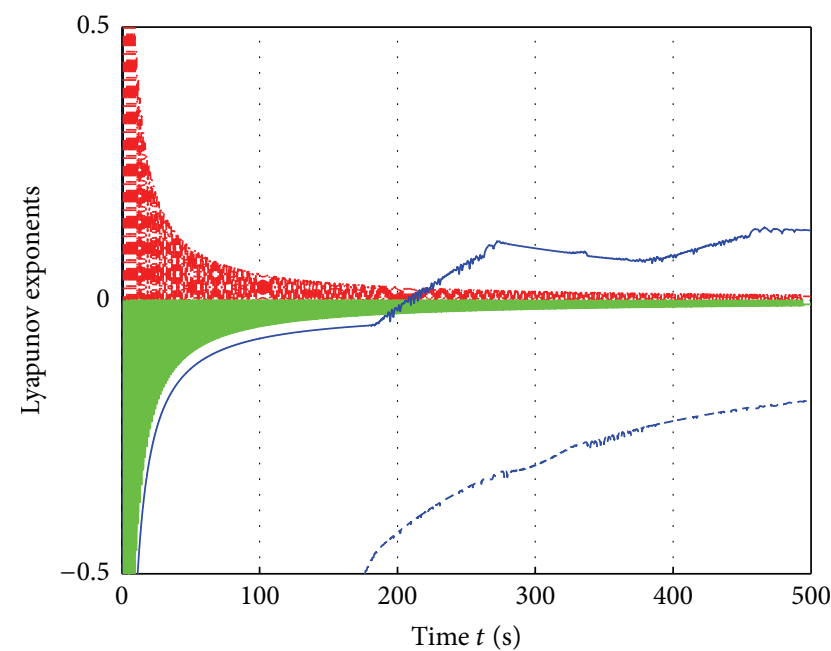

FIGURE 30: Lyapunov exponents $(A=0.02 \mathrm{rad}$, front-wheel-drive mode).

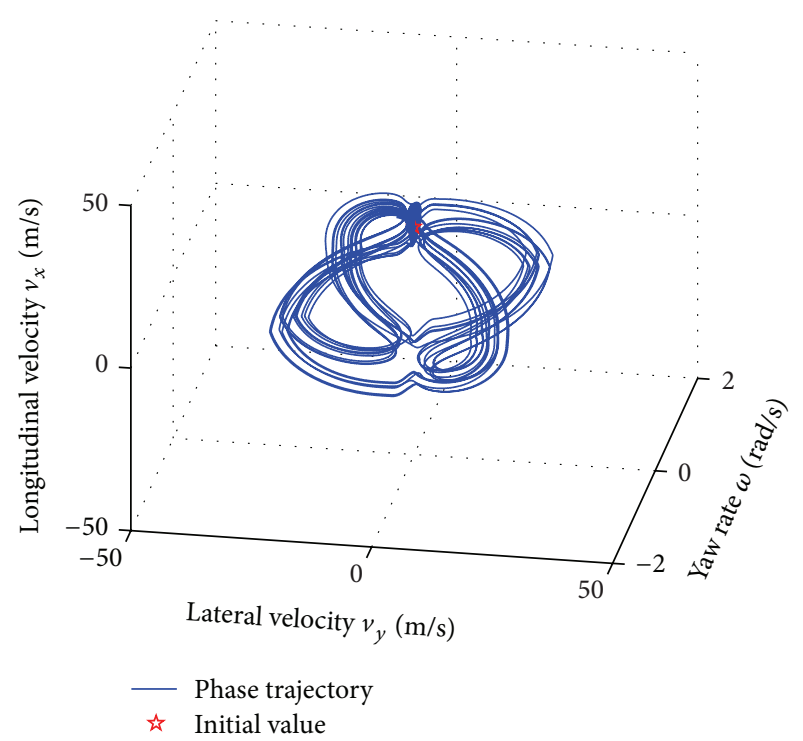

FIGURE 31: $v_{x}-v_{y}-\omega$ phase space trajectories $(A=0.04$ rad, frontwheel-drive mode).

achieves $\omega=-0.7982 \mathrm{rad} / \mathrm{s}$ at $t=470.1 \mathrm{~s}$. Finally, yaw rate returns to the post state range at $t=490 \mathrm{~s}$.

(3) The longitudinal velocity increases quickly again after decreases for three times consecutively. The minimum longitudinal velocity $v_{x}=-37.39 \mathrm{~m} / \mathrm{s}$ appears at $t=452.9 \mathrm{~s}$ to $37.39 \mathrm{~m} / \mathrm{s}$. When $t=459.4 \mathrm{~s}$, longitudinal velocity increases to the maximum $v_{x}=34.04 \mathrm{~m} / \mathrm{s}$. When $t=488 \mathrm{~s}$, the longitudinal velocity goes back to the previous steady state. And then the longitudinal velocity increases slowly.

Figure 27 is the phase trajectory of the Poincare section captured in period of front wheel steering angle. It can be seen from the picture that each state variable shows a limited point set, which is the typical characteristics of chaotic motion.

Figure 28 is the power spectral density diagram of each state variable. It is obvious that the lateral velocity and yaw 


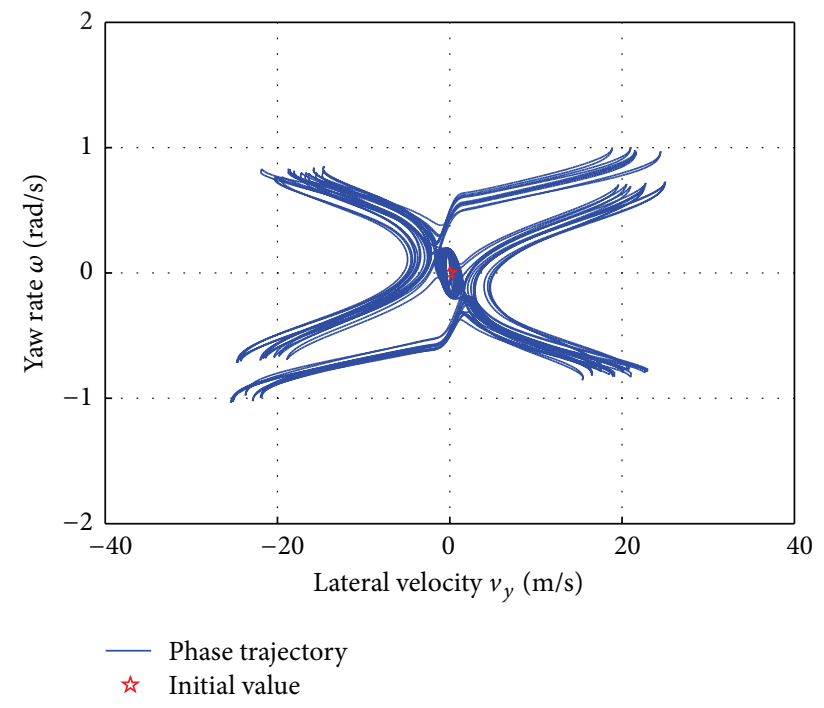

FIGURE 32: $v_{x}-v_{y}-\omega$ phase space portrait onto $v_{y}-\omega$ plane $(A=$ $0.04 \mathrm{rad}$, front-wheel-drive mode).
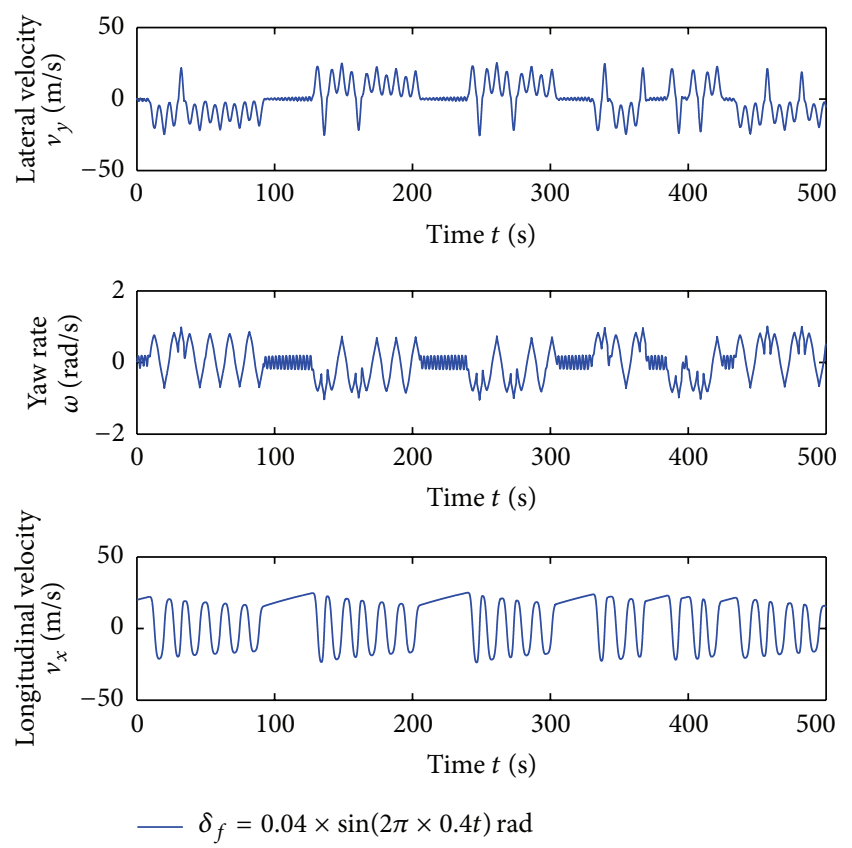

FIGURE 33: State variables ( $A=0.04 \mathrm{rad}$, front-wheel-drive mode).

rate show the broadband multipeak distribution characteristics of typical chaos. Compared with the power spectral density, while $A=0.015 \mathrm{rad}$, frequency range of longitudinal velocity and front and rear wheel rotational velocity is increased.

Figures 29 and 30 are the Lyapunov exponents of state variables.

Figure 29 is the local enlargement of Figure 30. When the simulation time $t=210 \mathrm{~s}$, system of Lyapunov exponents
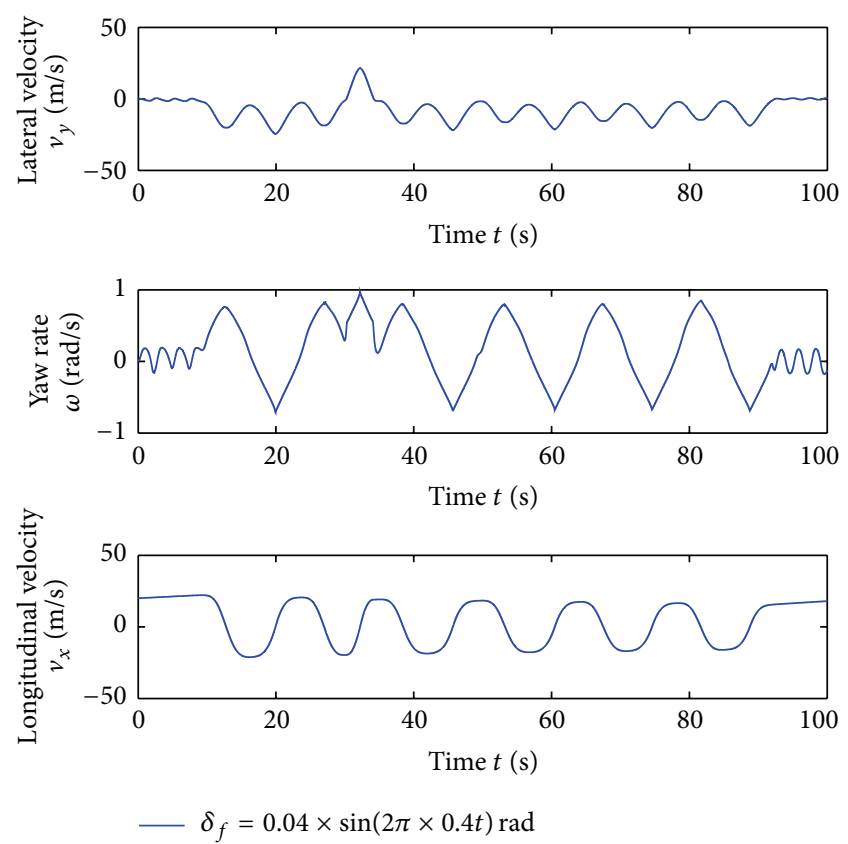

FIgURE 34: Part of state variables sequence $(A=0.04$ rad, frontwheel-drive mode).

spectrum turns from $(0,0,-,-,-,-)$ to $(+, 0,0,-,-,-,-)$, which is kept to the end of the whole simulation. This is the proof that the system enters the state of chaos.

4.3. Amplitude of Front Wheel Steering Angle $A=0.04 \mathrm{rad}$. Figures 31-38 are the simulation results with $A=0.04 \mathrm{rad}$. It is clear that the system bifurcation has occurred, and the system has completely entered into chaos state.

The phase space trajectories in Figures 31 and 32 show that the vehicle state has lost stability. In other words, the vehicle has entered into chaos. The state variables of time series in Figures 33 and 34 also show the severe oscillation. But its overall range is bounded. The Poincare section diagram in Figure 35 can also get the same conclusion that the Poincare section is the limited point set in bounded scope.

In Figure 36, the power spectral density of the state variables all presents the typical chaotic characteristics of broadband multimodal. Figures 37 and 38 are the Lyapunov exponents of state variables. It is obvious that, at the beginning of the simulation, the maximum Lyapunov exponent quickly stabilizes to the state in which maximum Lyapunov exponent is positive. It also shows that the system has completely entered into chaos.

\section{Conclusion}

(1) Under different driving conditions, vehicle steering and driving bifurcation characteristics exhibit obvious difference. So, the research on bifurcation characteristics without the driving mode is incomplete.

(2) The quasiperiodic torus rupture chaos route is proposed for 5DOF vehicle dynamics system; namely, with the 

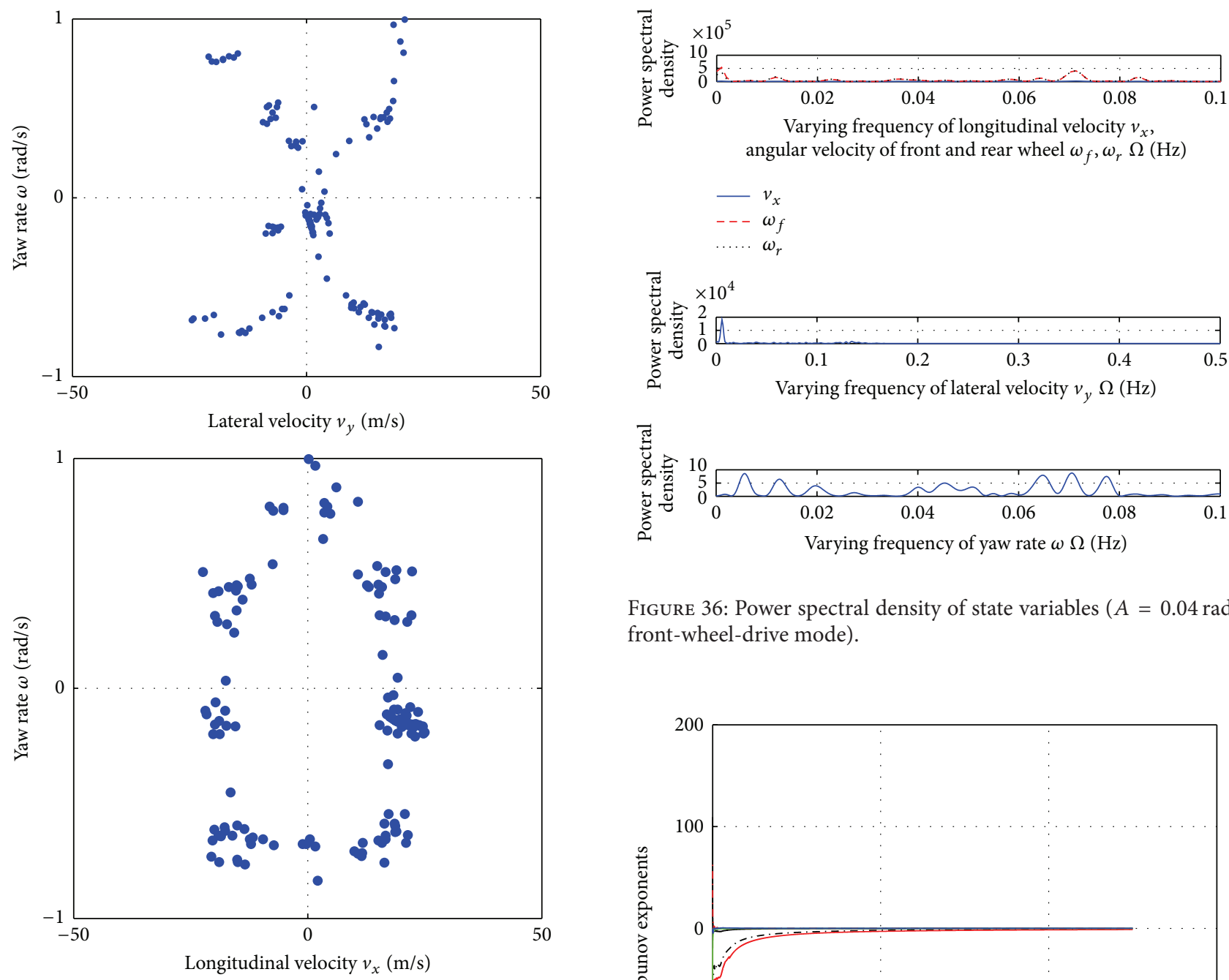

FIgURE 36: Power spectral density of state variables $(A=0.04 \mathrm{rad}$, front-wheel-drive mode).

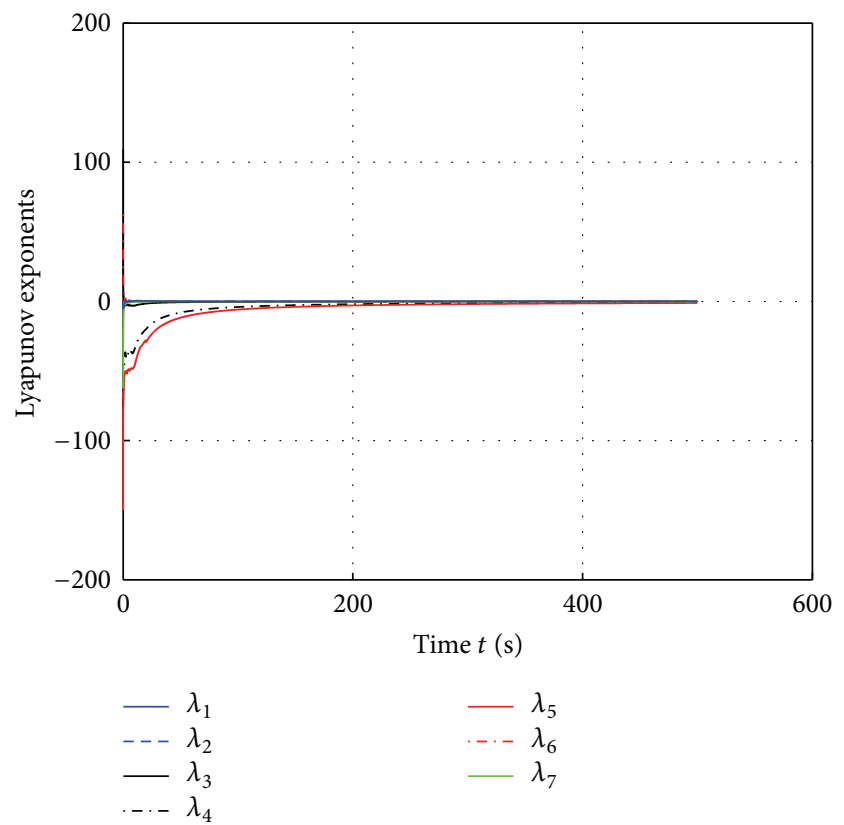

FIGURE 37: Lyapunov exponents $(A=0.04 \mathrm{rad}$, front-wheel-drive mode).

the essential characteristics of 5DOF vehicle dynamics system instability are the dynamic system chaotic motion.

\section{Conflict of Interests}

periodic front steering angle input, the stable quasiperiodic vehicle motion may turn into chaos. It is also proved that

The authors declare that there is no conflict of interests regarding the publication of this paper. 


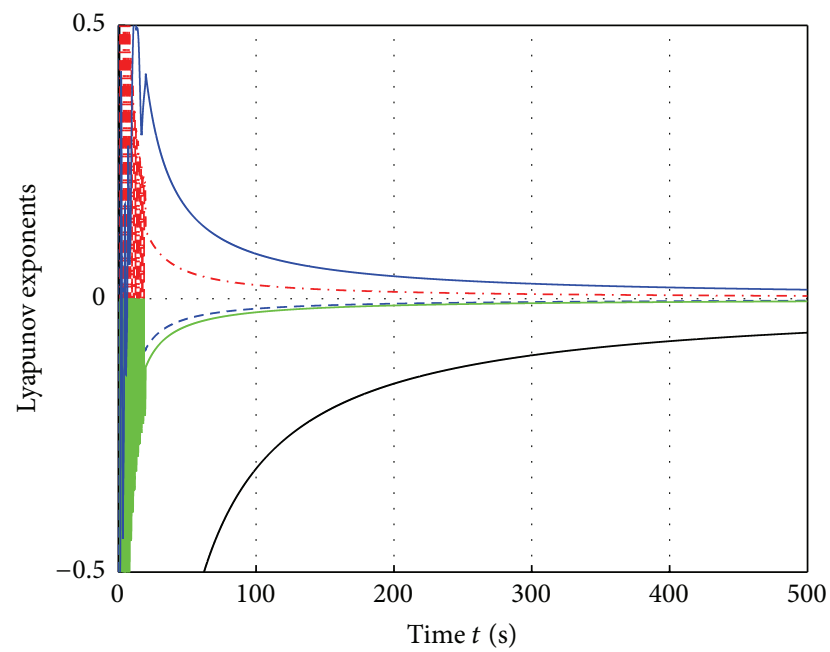

Figure 38: Lyapunov exponents $(A=0.04 \mathrm{rad}$, front-wheel-drive mode).

\section{Acknowledgments}

This project is supported by the National Natural Science Foundation of China (51475199), Natural Science Foundation of Heilongjiang Province of China (E2015052), and the Fundamental Research Funds for the Central Universities (2572015CB 15).

\section{References}

[1] F. D. Rossa, M. Gobbi, G. Mastinu, C. Piccardi, and G. Previati, "Bifurcation analysis of a car and driver model," Vehicle System Dynamics, vol. 52, supplement 1, pp. 142-156, 2014.

[2] F. Farroni, M. Russo, R. Russo, M. Terzo, and F. Timpone, "A combined use of phase plane and handling diagram method to study the influence of tyre and vehicle characteristics on stability," Vehicle System Dynamics, vol. 51, no. 8, pp. 1265-1285, 2013.

[3] S. Sadri and C. Wu, "Stability analysis of a nonlinear vehicle model in plane motion using the concept of Lyapunov exponents," Vehicle System Dynamics, vol. 51, no. 6, pp. 906-924, 2013.

[4] Y. Zhisheng, Vehicle Theory, China Machine Press, Beijing, China, 2009 (Chinese).

[5] G. S. Inagaki, L. Kushiro, and M. Yamamoto, "Analysis on vehicle stability in critical cornering using phase-plane method," in Proceedings of the International Symposium on Advanced Vehicle Control, SAE Paper 9438411, Tsukuba, Japan, 1994.

[6] E. Ono, S. Hosoe, H. D. Tuan, and S. Doi, "Bifurcation in vehicle dynamics and robust front wheel steering control," IEEE Transactions on Control Systems Technology, vol. 6, no. 3, pp. 412-420, 1998.

[7] E. Ono, S. Hosoe, H. D. Tuan, and S. Doi, "Robust stabilization of vehicle dynamics by active front wheel steering control," in Proceedings of the 35th IEEE Conference on Decision and Control, pp. 1777-1782, Kobe, Japan, December 1996.

[8] S. Shen, J. Wang, P. Shi, and G. Premier, "Nonlinear dynamics and stability analysis of vehicle plane motions," Vehicle System Dynamics, vol. 45, no. 1, pp. 15-35, 2007.
[9] L. Liu, J.-W. Chu, S.-M. Shi, and Y.-F. Zou, "Analysis on the influence of vehicle longitudinal acceleration on handling stability," Journal of Vibration and Shock, vol. 28, no. 6, pp. 145149, 2009.

[10] L. Liu, S. Shi, S. Shen, and J. Chu, "Vehicle planar motion stability study for tyres working in extremely nonlinear region," Chinese Journal of Mechanical Engineering, vol. 23, no. 2, pp. 185-194, 2010.

[11] S. Horiuchi, K. Okada, and S. Nohtomi, "Analysis of accelerating and braking stability using constrained bifurcation and continuation methods," Vehicle System Dynamics, vol. 46, no. 1, pp. $585-597,2008$

[12] X. Wang, S. Shi, L. Liu, and L. Jin, "Analysis of driving mode effect on vehicle stability," International Journal of Automotive Technology, vol. 14, no. 3, pp. 363-373, 2013.

[13] U. Kiencke and L. Nielsen, Automotive Control Systems, Springer, New York, NY, USA, 2000.

[14] H. B. Pacejka, Tyre and Vehicle Dynamic, Elsevier, Oxford, UK, 2006.

[15] V. Nguyen, Vehicle handling, stability, and bifurcation analysis for nonlinear vehicle models [Master dissertation], University of Maryland, Washington, DC, USA, 2005.

[16] A. Wolf, J. B. Swift, H. L. Swinney, and J. A. Vastano, "Determining Lyapunov exponents from a time series," Physica D, vol. 16, no. 3, pp. 285-317, 1985. 


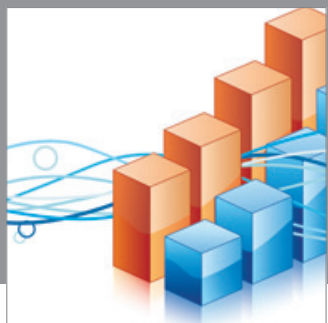

Advances in

Operations Research

mansans

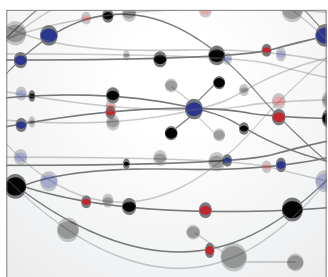

The Scientific World Journal
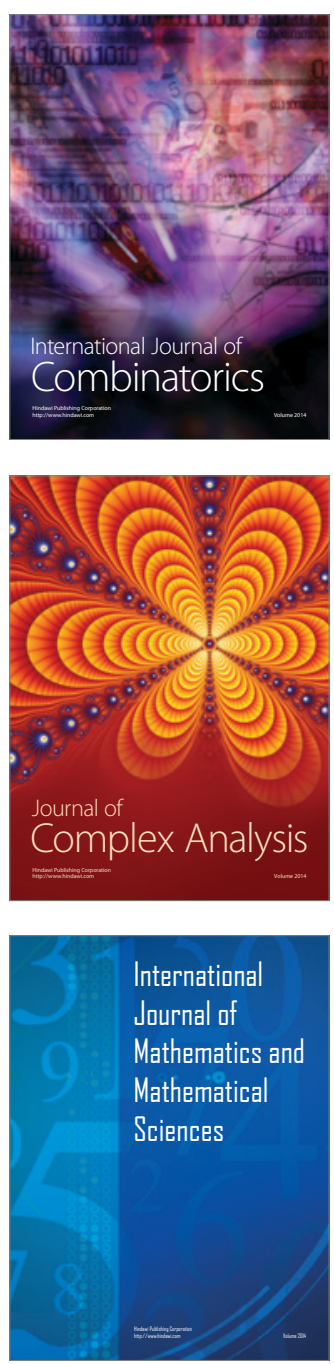
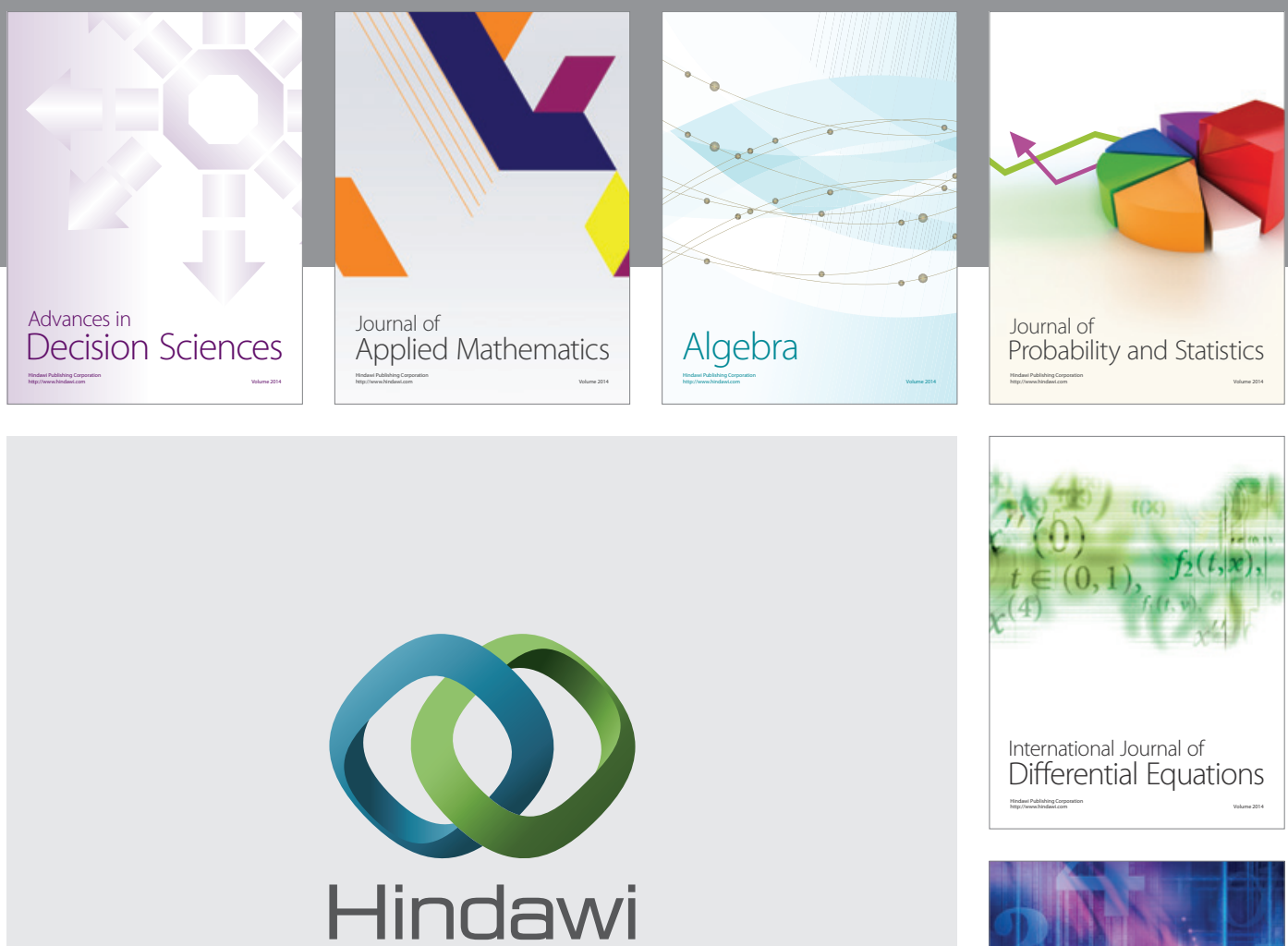

Submit your manuscripts at http://www.hindawi.com
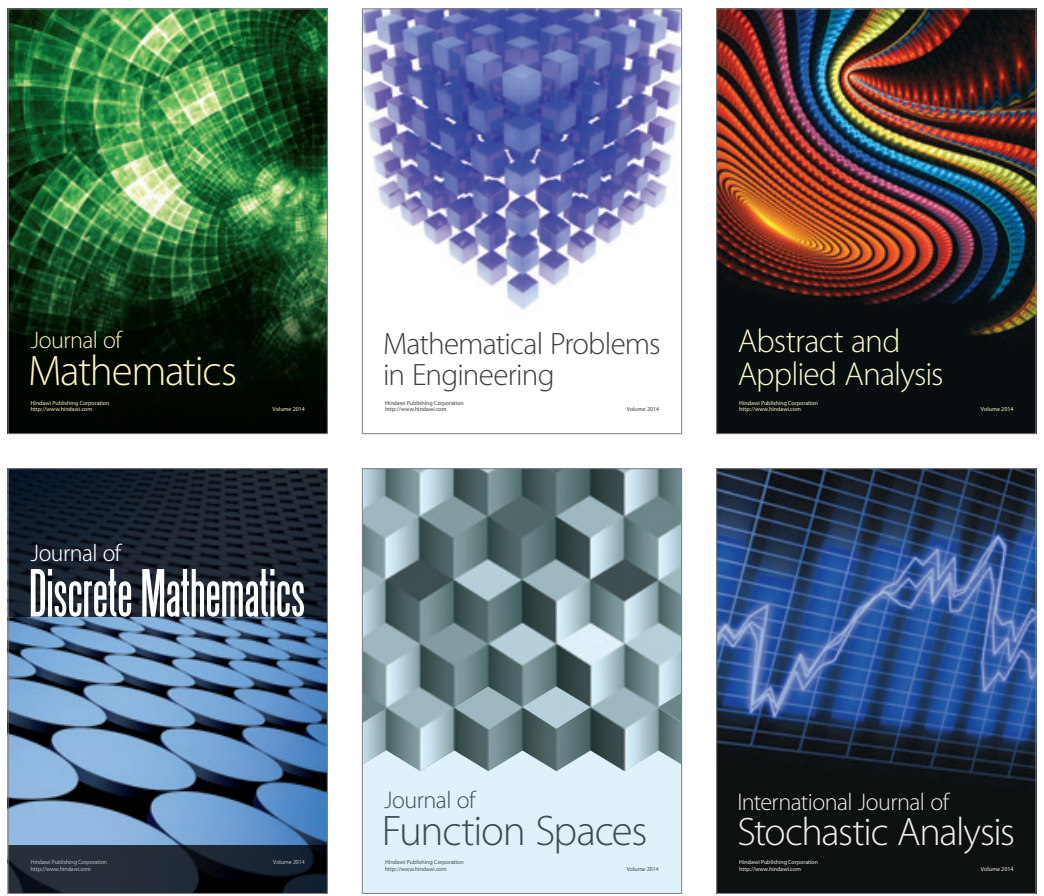

Journal of

Function Spaces

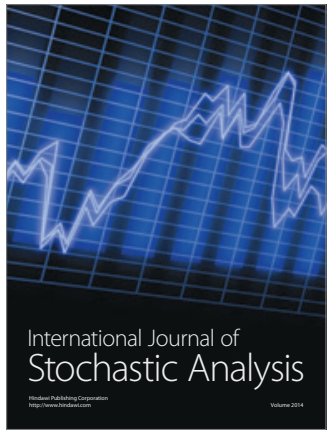

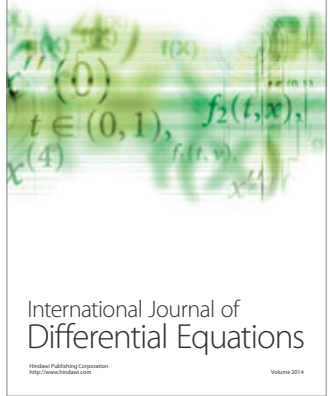
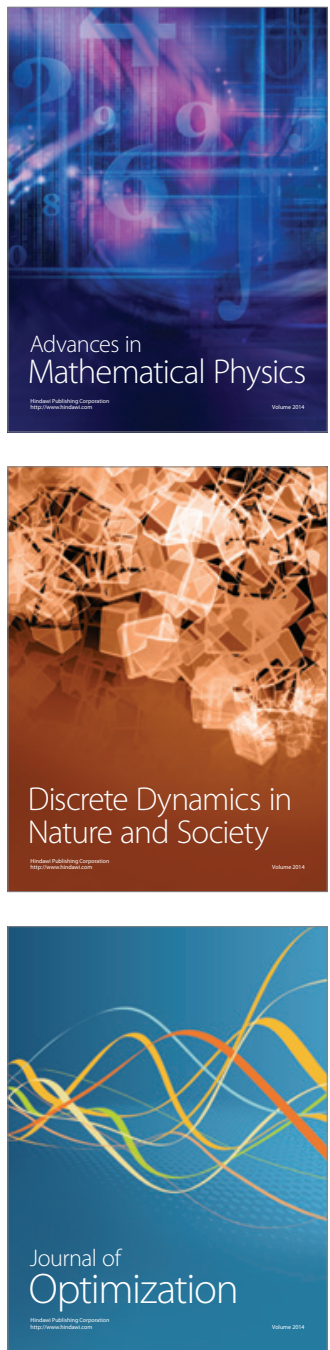